\title{
Nucleolin Targeting by N6L Inhibits Wnt/ $\beta$-Catenin Pathway Activation in Pancreatic Ductal Adenocarcinoma
}

\author{
Fabio Raineri ${ }^{1}$, Sandrine Bourgoin-Voillard ${ }^{1,2,3,4}{ }^{\oplus}$, Mélissande Cossutta ${ }^{1,5}{ }^{(}$, Damien Habert ${ }^{1}$, Matteo Ponzo ${ }^{1}$, \\ Claire Houppe ${ }^{1}$, Benoît Vallée ${ }^{1}$, Michele Boniotto ${ }^{1}$, Mounira Chalabi-Dchar ${ }^{6}$, Philippe Bouvet ${ }^{6,7} \mathbb{D}$, \\ Anne Couvelard ${ }^{8}$, Jerome $\operatorname{Cros}^{8}{ }^{(1)}$, Anais Debesset ${ }^{1}$, José L. Cohen ${ }^{1,5}{ }^{-}$, José Courty ${ }^{1,5}$ and Ilaria Cascone ${ }^{1,5, *(\mathbb{C})}$
}

Citation: Raineri, F;

Bourgoin-Voillard, S.; Cossutta, M.; Habert, D.; Ponzo, M.; Houppe, C.; Vallée, B.; Boniotto, M.; Chalabi-Dchar, M.; Bouvet, P.; et al. Nucleolin Targeting by N6L Inhibits Wnt/ $\beta$-Catenin Pathway Activation in Pancreatic Ductal Adenocarcinoma Cancers 2021, 13, 2986. https:// doi.org/10.3390/cancers13122986

Academic Editors: Louis BUSCAIL and Niccola Funel

Received: 30 March 2021

Accepted: 10 June 2021

Published: 15 June 2021

Publisher's Note: MDPI stays neutral with regard to jurisdictional claims in published maps and institutional affiliations.

Copyright: (C) 2021 by the authors. Licensee MDPI, Basel, Switzerland. This article is an open access article distributed under the terms and conditions of the Creative Commons Attribution (CC BY) license (https:// creativecommons.org/licenses/by/ $4.0 /)$.
1 University Paris Est Créteil, INSERM, IMRB, 94010 Créteil, France; fabio.raineri@inserm.fr (F.R.); sandrine.bourgoin@univ-grenoble-alpes.fr (S.B.-V.); melissande.cossutta@inserm.fr (M.C.); damien.habert@u-pec.fr (D.H.); matteo.ponzo@ircc.it (M.P.); claire.justine-houppe@inserm.fr (C.H.); b.vallee@u-pec.fr (B.V.); michele.boniotto@inserm.fr (M.B.); anais.debesset@inserm.fr (A.D.); jose.cohen@inserm.fr (J.L.C.); courty@u-pec.fr (J.C.)

2 University of Grenoble Alpes, CNRS, Grenoble INP, Inserm U1055, LBFA and BEeSy, PROMETHEE Proteomic Platform, 38400 Saint-Martin d'Heres, France

3 University of Grenoble Alpes, CNRS, Grenoble INP, TIMC, PROMETHEE Proteomic Platform, 38000 Grenoble, France

4 CHU Grenoble Alpes, Institut de Biologie et de Pathologie, 38043 Grenoble, France

5 AP-HP, Groupe Hospitalo-Universitaire Chenevier Mondor, Centre d'Investigation Clinique Biotherapie, 94010 Créteil, France

6 Centre de Recherche en Cancérologie de Lyon, Cancer Cell Plasticity Department, University of Lyon, UMR INSERM 1052 CNRS 5286, Centre Léon Bérard, 69008 Lyon, France; mounira.chalabi@lyon.unicancer.fr (M.C.-D.); philippe.bouvet@ens-lyon.fr (P.B.)

7 University of Lyon, Ecole Normale Supérieure de Lyon, 69342 Lyon, France

8 Département de Pathologie, Hôpital Bichat APHP DHU UNITY, 75018 Paris, France; anne.couvelard@aphp.fr (A.C.); Jerome.cros@aphp.fr (J.C.)

* Correspondence: ilaria.cascone@u-pec.fr; Tel.: +33-149-813-765

Simple Summary: Pancreatic ductal adenocarcinoma (PDAC) is an aggressive cancer that has no effective treatment. Nucleolin targeting by the pseudopeptide N6L inhibits the tumor growth and metastasis of pancreatic ductal adenocarcinoma (PDAC). Here, we explored the pathways regulated by nucleolin and N6L in PDAC. We demonstrated that both interact with $\beta$-catenin, and that the Wnt/ $\beta$-catenin pathway is activated in PDAC mouse models. Nucleolin inhibition decreases Wnt/ $\beta$ catenin pathway activation in PDAC cells and tumors, and represents a new druggable pathway regulated by nucleolin.

Abstract: Pancreatic ductal adenocarcinoma (PDAC) is a highly aggressive and resistant cancer with no available effective therapy. We have previously demonstrated that nucleolin targeting by N6L impairs tumor growth and normalizes tumor vessels in PDAC mouse models. Here, we investigated new pathways that are regulated by nucleolin in PDAC. We found that N6L and nucleolin interact with $\beta$-catenin. We found that the Wnt/ $\beta$-catenin pathway is activated in PDAC and is necessary for tumor-derived 3D growth. N6L and nucleolin loss of function induced by siRNA inhibited Wnt pathway activation by preventing $\beta$-catenin stabilization in PDAC cells. N6L also inhibited the growth and the activation of the Wnt/ $\beta$-catenin pathway in vivo in mice and in $3 \mathrm{D}$ cultures derived from MIA PaCa2 tumors. On the other hand, nucleolin overexpression increased $\beta$-catenin stabilization. In conclusion, in this study, we identified $\beta$-catenin as a new nucleolin interactor and suggest that the Wnt/ $\beta$-catenin pathway could be a new target of the nucleolin antagonist N6L in PDAC.

Keywords: pancreatic ductal adenocarcinoma; nucleolin; N6L; Wnt/ $\beta$-catenin pathway; tumor microenvironment; cancer therapy 


\section{Introduction}

Pancreatic ductal adenocarcinoma (PDAC) is one of the most aggressive and lethal cancers. The incidence rate continues to increase for this type of cancer, and only $9 \%$ of PDAC patients survive beyond 5 years [1], often due to late symptom onset and diagnosis.

Nucleolin is overexpressed in several tumors and in pancreatic ductal adenocarcinoma (PDAC); 74.5\% of patients have a high level of this protein's expression, and it correlates with a poor prognosis [2,3]. Nucleolin is a nucleocytoplasmic protein involved in ribosomal assembly and mRNA metabolism, promoting cell proliferation and survival of tumor cells [4]. Our group patented the nucleolin antagonist N6L, which shows antitumor activities in breast cancer [5], prostate cancer [6], leukemia [7], non-small cell lung carcinoma [8], brain tumors $[9,10]$, and pancreatic ductal adenocarcinoma $[2,11]$, and furthermore can be coupled to nanoparticles [11-13] or toxins [10].

The Wnt/ $\beta$-catenin signaling pathway has a central role in embryogenesis and is dysregulated in several types of cancers $[14,15]$. It enhances cell proliferation, migration, and survival. When the Wnt $/ \beta$-catenin signaling pathway is not active, $\beta$-catenin is phosphorylated by casein kinase 1 (CK1) and glycogen synthase kinase $3 \beta$ (GSK3 $\beta)$, ubiquitinated by $\beta$-transducin repeat-containing protein $(\beta-\operatorname{TrCP})$ and degraded by the proteasome [16]. The activation of the pathway by Wnt ligands to the receptor Frizzled $[17,18]$ induces the accumulation of $\beta$-catenin, and the transcription of target genes $[19,20]$. The Wnt $/ \beta$-catenin pathway seems to be involved in carcinogenesis and progression of PDAC [21-24].

We are investigating molecular pathways in order to find new diagnostic markers and therapeutic targets in PDAC, in order to develop more effective therapies. N6L localizes to tumor tissue and reduces tumor growth by inducing apoptosis and inhibiting cell proliferation [2,5]. However, the mechanism of its effects on tumor cell growth was still unclear. The aim of this work was to investigate new molecular interactors of nucleolin, and we found that the Wnt/ $\beta$-catenin pathway is a new pathway that is inhibited by N6L in PDAC.

\section{Results}

\subsection{N6L Interacts with $\beta$-Catenin}

The nucleolin antagonist N6L inhibits PDAC tumor growth by impairing tumor cell proliferation and survival [2]. We sought to investigate the mechanism of action of N6L by studying the N6L interactome in PDAC cells. Since N6L binds to extranuclear nucleolin, an approach of N6L pull-down of the extranuclear cellular fraction of PDAC cells and identification of proteins by mass-spectrometry was applied. Increasing concentrations of biotinylated-N6L were incubated on murine PDAC (mPDAC) cells. Cells were lysed with a specific protocol to harvest only the extranuclear fraction of cells [25], and proteins bound to biotinylated-N6L were isolated by a pull-down assay. Protein bands showed an increasing intensity from $5 \mu \mathrm{M}$ to $10 \mu \mathrm{M}$ in biotinylated-N6L pull-down samples, supporting a dose-dependent efficacy of the interaction with N6L (Figure S1).

Bands of proteins from the $10 \mu \mathrm{M}$ biotinylated-N6L pull-down sample or from the pull-down of biotin alone were processed for mass-spectrometry analysis (Table S1). Nonspecific proteins found in the negative control were subtracted from the list of the specific proteins interacting with N6L. Forty-five proteins were identified as N6L partners (Table S1). Nucleolin and 18 known interactors of nucleolin, such as integrin $\alpha \mathrm{v} \beta 3$ [26], belong to the list of $45 \mathrm{~N} 6 \mathrm{~L}$ partners (Table S1). The gene ontology (GO) of the 45 proteins pulled down by N6L is built in a ClueGO network by using Cytoscape software and larger hexagons have lower $p$-value (Figure 1A). The more highly represented biological processes were the ones in which nucleolin was involved, such as "regulation of rRNA processing", "ribosomal large and small subunit biogenesis", "mRNA stabilization", and "regulation of translational initiation" (Figure 1A). The same statistically overrepresented biological processes were obtained by GO enrichment analysis (Table S2). This evidence supported the idea that this approach isolated specific N6L targets and could be used to find new N6L targets. We were interested in the biological process of "response to antineoplastic 
agents", in which we identified $\beta$-catenin as a new interesting potential target of N6L. The interaction between $\beta$-catenin and N6L was validated by a pull-down assay in murine (mPDAC) and two human (MIA PaCa-2 and Panc-1) PDAC cells. $\beta$-catenin and nucleolin were present in N6L pull-down of mPDAC (Figure 1B), MIA PaCa-2 (Figure 1C), and Panc-1 (Figure S3A) cells.

A
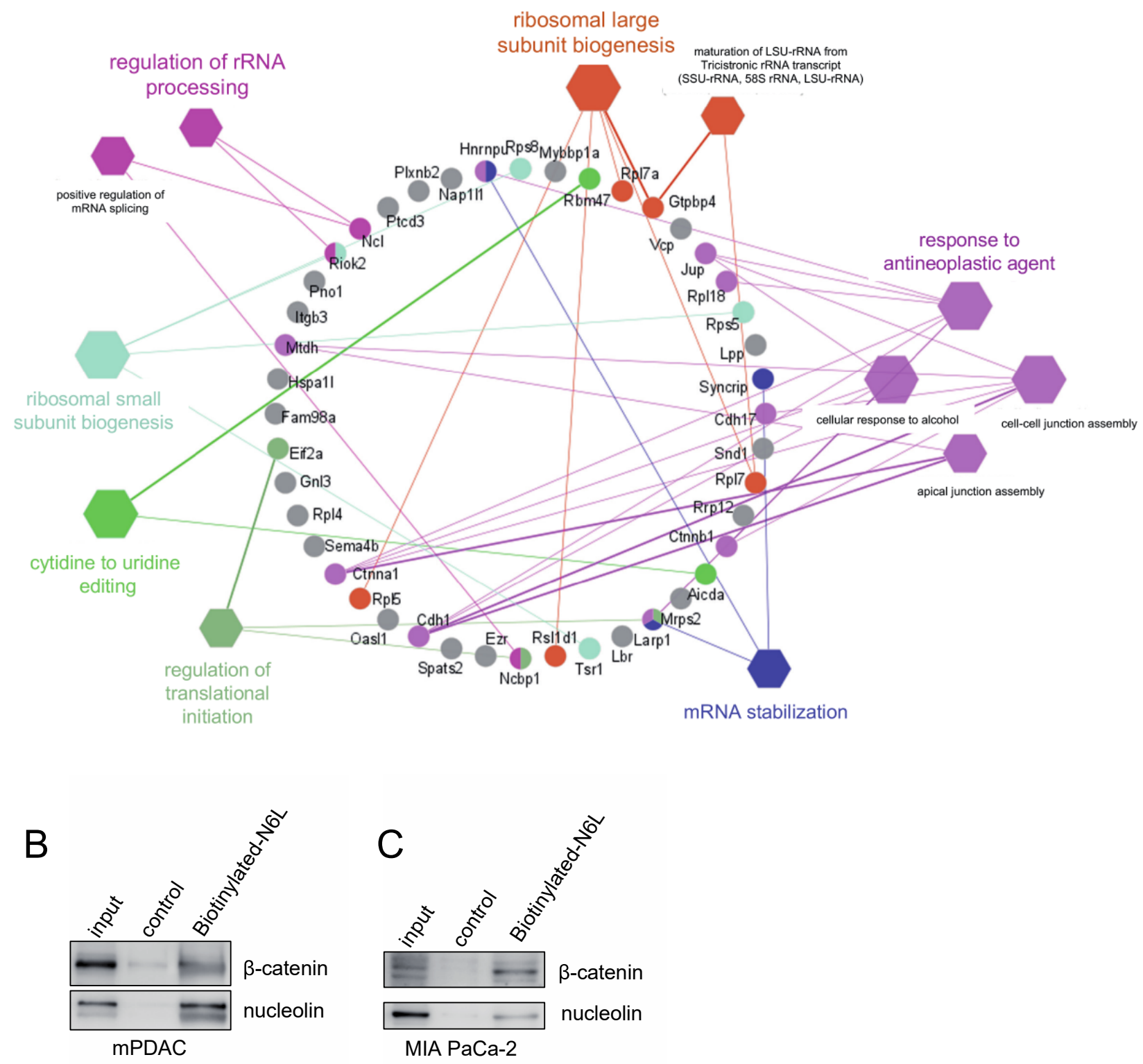

Figure 1. Proteins from N6L pull-down and their biological functions. (A) ClueGO network of non-redundant biological processes for N6L interactome (Cytoscape version 3.8.0, ClueGO version 2.5.6/CluePedia/GO_BiologicalProcess-EBIUniProt-GOA_21.04.2020 with 21201 references). Functionally grouped network with terms (in hexagons) as nodes linked based on their kappa score level $(\geq 0.4)$, where only the label of the most significant term per group is shown. The hexagon node size represents term $p$-value corrected with Bonferroni step-down level $(\leq 0.05)$ (larger size for lower $p$-value). The nodes in the circle represent the genes and the edges represent the links with the biological process group. Functionally related groups partially overlap for the same gene. Gene terms not related to a functional group are shown in grey. $(B, C)$ Western blotting of N6L pull-down. The cell lysate of the extranuclear cellular fraction (input), the biotinylated N6L pull-down and the control biotin pull-down of mPDAC and MIA PaCa-2 cells were analyzed by Western blotting with anti-nucleolin and anti- $\beta$-catenin antibodies. 


\subsection{N6L Inhibits the Activation of the Wnt/ $\beta$-Catenin Pathway and Prevents $\beta$-Catenin Stabilization}

$\beta$-catenin is important for carcinogenesis and tumor progression of PDAC (Ram Makena et al., 2019) [27]. A N6L network (N6L interactome), integrating the 45 N6L partners and the known interactors of these partners from the STRING database, was built by using the Cytoscape software (Figure S2) and following the methods previously described and detailed in Supplementary Materials [28,29]. We observed that $\beta$-catenin was the key node between the N6L interactome generated by the 45 proteins isolated by the N6L pull-down and Wnt/ $\beta$-catenin signaling pathway (Figure S2). Pre-clinical evidence suggests that inhibition of Wnt/ $\beta$-catenin signaling can impair tumor growth [15]. Since we observed that N6L interacts with $\beta$-catenin, we wondered if N6L could impact the activation of the Wnt/ $\beta$-catenin pathway. mPDAC, human MIA PaCa-2, and Panc- 1 cells were transfected with plasmids containing a $\beta$-catenin responding gene (Firefly luciferase) and a control gene (Renilla luciferase). Wnt3A was prepared from the conditioned media of L-Wnt-3A cells, produced, and recovered as described by Shibamoto et al. [30]. All cell lines were stimulated with Wnt3A conditioned media (Wnt3A-CM) for $24 \mathrm{~h}$, and the activation of the $\beta$-catenin pathway was measured as the fold change of the luciferase activity (Figure 2A-C). Wnt3A-CM increased the luciferase activity 6.1-fold in mPDAC, 5.4-fold in MIA PaCa-2 cells, and 3-fold in Panc-1 cells, relative to controls (Figure 2A-C, respectively). N6L significantly inhibited luciferase activity 2.2-fold in Wnt3A-stimulated mPDAC murine cells relative to Wn3A-stimulated cells, but not in unstimulated cells (Figure 2A). In human PDAC cells lines, N6L impaired luciferase activity 2.16-fold and 5 -fold in MIA PaCa-2 and Panc-1 cells, respectively (Figure 2B,C). In order to further understand the impact of N6L on the Wnt/ $\beta$-catenin pathway, we investigated the stabilization of the protein $\beta$-catenin, which is the first event of the pathway activation. MIA PaCa-2 cells are the only human cell line, of seven different cell lines, with a low basal protein level of $\beta$-catenin, because it is constitutively degraded by the proteasome after being phosphorylated by CK1 and GSK3 $\beta$ [31-33]. The other human cell lines, including Panc-1 cells, have a high basal protein level of $\beta$-catenin [31-33] (Figure S3B). We stimulated MIA PaCa-2 cells and Panc- 1 cells with Wnt3A-CM and followed the stabilization of $\beta$-catenin protein levels by Western blotting (Figure 2D,E and Figure S3B,C). MIA PaCa-2 cells showed a peak of an increase of $\beta$-catenin levels after $3 \mathrm{~h}$ of Wnt-3A stimulation, and this time point was chosen for the study of the $\beta$-catenin stabilization in MIA PaCa-2 cells (Figure S3B). Panc- 1 cells did not show, as expected, a clear stabilization of $\beta$-catenin under Wnt3A stimulation at different time points, probably due to the high basal level of the protein in control cells (Figure S3C). The stimulation of MIA PaCa-2 cells, but not of Panc- 1 cells, by Wnt $3 \mathrm{~A}$ induces a localization of the $\beta$-catenin protein into the nucleus (Figure S3D). As MIA PaCa- 2 cells responded to Wnt3A stimulation, we tested the effect of N6L on $\beta$-catenin stabilization in this cell line. After $3 \mathrm{~h}$, Wnt-3A stimulation induced a 5 -fold increase of the $\beta$-catenin levels (Figure 2D,E). The active fraction of $\beta$-catenin was studied by using a nonphosphorylated $\beta$-catenin antibody [30] (Figure 2D,F) of the non-phosphorylated $\beta$-catenin form as a marker of the correct inhibition of the $\beta$-catenin destruction machinery (APC, Axin, CK1, and GSK3 $\beta$ ) after activation of the pathway. Non-phosphorylated $\beta$-catenin protein levels increased 5.2-fold in Wnt3A-CM MIA PaCa-2 stimulated cells compared to control cells (Figure 2D,F). The treatment of Wnt3A-stimulated cells by N6L completely inhibited the increase of the $\beta$-catenin and non-phosphorylated $\beta$-catenin protein level induced by Wnt3A-CM, but did not change the level of both forms of the protein in unstimulated cells (Figure 2D-F). The status of GSK3 $\beta$ activation in this setting was analyzed by using an antibody against the phosphorylation of Serine 9 that recognizes the inactive form of the kinase. The amount of phoshpo-Ser9-GSK3 $\beta$ was inhibited by the N6L-Wnt3A treatment compared to Wnt3A (Figure 2D,G). A GSK3 $\beta$ inhibitor was used to better investigate the mechanism by which N6L impacts $\beta$-catenin stabilization. GSK3 $\beta$ is the kinase responsible for the phosphorylation of $\beta$-catenin, causing its proteasomal destruction [16]. The treatment of MIA PaCa-2 cells for 30 min with TWS119, a GSK3 $\beta$ inhibitor that prevents $\beta$-catenin phosphorylation and degradation, induced a 2-fold increase in the protein's 
accumulation compared to the control (Figure 2H,I). N6L abrogated $\beta$-catenin stabilization by TWS119 (Figure 2H,I). The expression of the Wnt-related target genes AXIN2 and Cyclin D1, usually followed downstream of the activation of the pathway [34], were analyzed. After $24 \mathrm{~h}$ of treatment, N6L significantly inhibited the accumulation of active $\beta$-catenin, and the increased expression of AXIN2 and CyclinD1 induced by Wnt3A-CM (Figure 2J-L). Together, these results suggest that N6L regulates $\beta$-catenin stabilization and functions through GSK3 $\beta$.

\subsection{Nucleolin Promotes $\beta$-Catenin Stabilization under Wnt3A Stimulation}

Since N6L is an antagonist of nucleolin, and as we showed by pull-down experiments that N6L interacts with nucleolin and $\beta$-catenin, we evaluated the role of nucleolin in Wnt/ $\beta$-catenin pathway activation. Nucleolin was immunoprecipitated from MIA PaCa-2 cells that were stimulated or not with Wnt3A-CM for $3 \mathrm{~h}$ (Figure 3A). Western blotting analysis showed that $\beta$-catenin was in the nucleolin immunoprecipitate in basal nonstimulated ( - ) cells, and that its amount increased after Wnt3A stimulation (Figure 3A). The interaction between $\beta$-catenin and nucleolin was confirmed in PAnc- 1 cells by immunoprecipitation (Figure 3A). In order to study the role of nucleolin in the Wnt/ $\beta$-catenin pathway, we performed both loss and gain of function experiments. MIA PaCa-2 cells were depleted of nucleolin by previously validated siRNAs (Gilles et al., 2016) [2], and were stimulated or not with Wnt3A. Wnt3A treatment increased the amount of the nonphosphorylated form of $\beta$-catenin in siControl cells, and to a lesser extent, in siNCL cells (Figure 3B,C). The level of non-phosphorylated $\beta$-catenin under Wnt3A stimulation in siNCL cells was about 2.8-fold lower than in the siControl cells (Figure 3C). In a gain-offunction approach, MIA PaCa-2 cells were transfected by a plasmid containing an NCL-GFP fusion gene (NCL) or a GFP plasmid (e) as control (Figure 3D,E). NCL-GFP expression increase 2.3-fold the accumulation of the non-phosphorylated form of $\beta$-catenin, compared to cells transfected with empty plasmids, under Wnt3A stimulation (Figure 3D,E). These results together suggested that nucleolin participates in Wnt/ $\beta$-catenin pathway activation via $\beta$-catenin stabilization.

\subsection{Wht/ $\beta$-Catenin Pathway Activation Specifically Sensitizes Cells to N6L Targeting}

We sought to investigate the role of Wnt / $\beta$-catenin pathway activation on the viability of PDAC cells. MIA PaCa-2 cell viability was measured after stimulation with Wnt3A (Figure 4). Stimulation with Wnt3A for 24 or $72 \mathrm{~h}$ did not change the viability of MIA PaCa2 cells compared to the control (Figure 4A,B, respectively), suggesting that the activation of the Wnt/ $\beta$-catenin pathway alone was not sufficient to induce cell growth. Wnt3Astimulated cells were treated by IWR-1-endo, an inhibitor of the Wnt/ $\beta$-catenin pathway, or by gemcitabine, the standard of care of PDAC, or by N6L, for 24 and $72 \mathrm{~h}$ (Figure 4A,B). IWR-1-endo stabilizes Axin after the activation of the pathway by Wnt3A [35], maintaining the destruction complex and promoting the degradation of $\beta$-catenin. IWR-1-endo at $20 \mu \mathrm{M}$ alone did not change the cell viability but slightly decreased the viability of cells treated with Wnt3A-CM at 24 and $72 \mathrm{~h}$, compared to the treatment with IWR-1-endo alone (Figure 4A,B). N6L inhibited cell viability at $24 \mathrm{~h}$ and at $72 \mathrm{~h}$. N6L $10 \mu \mathrm{M}$ decreased viability by $25 \%$ and N6L $30 \mu \mathrm{M}$ by $59.5 \%$, respectively (Figure $4 \mathrm{~A}, \mathrm{~B}$ ). A significantly increased effect on cell viability was observed in the condition of Wnt3A-CM/N6L $10 \mu \mathrm{M}$ compared to N6L $10 \mu \mathrm{M}$ alone at $72 \mathrm{~h}$, and in the condition of Wnt3A-CM/N6L $30 \mu \mathrm{M}$ compared to N6L $30 \mu \mathrm{M}$ alone, at both 24 and $72 \mathrm{~h}$ (Figure 4A,B). Wnt3A treatment did not improve gemcitabine sensitivity to cell viability compared to gemcitabine alone (Figure 4A,B). The synergistic effect of the combination of the treatment with Wnt3A stimulation on cell viability was calculated by using Combenefit (the High Single Agent model) [36] (Figure 4C), and IWR-1-endo showed a synergistic effect in the presence of Wnt3A stimulation, compared to treatments alone (Figure 4C). N6L, but not gemcitabine, had a significant synergistic effect in the presence of Wnt3A stimulation, and the effect increased with increasing concentrations of N6L (Figure 4C). Since N6L induces PDAC 
cell apoptosis and decreases cell proliferation [2], the impact of Wnt3A and N6L on MIA PaCa-2 cell apoptosis and proliferation was evaluated. N6L decreased MIA PaCa-2 cell proliferation 1.7-fold (Figure 4D) and increased cell apoptosis 4-fold (Figure 4E). Wnt3A did not impact either cell proliferation or cell apoptosis, but the combination of N6L with Wnt3A significantly increased the effect of N6L on both cellular processes by 1.6 and 2.3-fold, respectively (Figure $4 \mathrm{D}, \mathrm{E}$ ). These results suggested that the activation of the Wnt $/ \beta$-catenin pathway could sensitize cells to the anti-proliferative and pro-apoptotic impact of N6L.

\subsection{Wnt/ $\beta$-Catenin Pathway Activation Is Essential for the Generation and Progression of MIA PaCa-2 Tumor-Derived 3D Culture}

The tumor-derived 3D cultures were established from MIA PaCa-2 tumors generated in immunodeficient mice by using the complete feeding medium (CFM), enriched by many growth factors and Wnt3A-CM, as previously described in published protocols [37,38]. Tumor-derived 3D culture derived from MIA PaCa-2 tumors grown in CFM reproduced an epithelial-lined cystic structure, as previously described [37,38] (Figure 5A, Wnt3A+ arrows). To evaluate the importance of Wnt3A, we prepared a medium of culture deprived of Wnt3A-CM. Tumor-derived 3D culture derived from MIA PaCa-2 tumors and culture in the absence of Wnt3A grew slower and mostly formed small irregular masses of cells (Figure 5A, Wnt3A, arrows). This suggests that Wnt $/ \beta$-catenin pathway activation is necessary for the establishment and growth of MIA PaCa-2 tumors in 3D culture, compared to the cell 2D culture of Figure 4. Tumor-derived 3D cultures grown in the presence of Wnt3ACM were treated or not with N6L $30 \mu \mathrm{M}$ for $24 \mathrm{~h}$. They were fixed and immunostained for active $\beta$-catenin and cyclin D1 (arrows in Figure 5B,E, respectively). Tumor-derived 3D culture with Wnt3A-CM, but not treated with N6L (control), showed high immunostaining for active $\beta$-catenin (arrows in Figure 5B). Active $\beta$-catenin was mostly cytoplasmic, and no signal was evident in the nuclei of 3D cultures (Figure 5B). As it has been previously shown, endogenous $\beta$-catenin localizes to the nucleus after a short time point of Wnt3a stimulation and then nuclear staining decreases thereafter [39]. In Figure 5B, the absence of nuclear active $\beta$-catenin is probably due to persistent and non-transient Wnt3A stimulation in the growth medium, as it was observed in organoid culture of primary mouse colon tumors [40]. Nuclear Cyclin D1 staining is strong (arrows in Figure 5E). MIA PaCa-2 3D cultures treated with N6L were smaller than the controls (Figure 5C). Active $\beta$-catenin staining and nuclear cyclin D1 signals decreased after N6L treatment (Figure 5B,D-F, respectively). These results demonstrated that N6L affects Wnt/ $\beta$-catenin pathway activation in 3D cultures derived from MIA PaCa- 2 tumors. To support the importance of $\mathrm{Wnt} / \beta$-catenin activation in human PDAC, we analyzed active $\beta$-catenin protein levels in 45 tumors in TMA. A total of $73.3 \%$ of the tumors had a high score (Figure S4A,D), $17.7 \%$ an intermediate score (Figure S4B,D), and $8.8 \%$ a low score for staining (Figure S4C,D).

\subsection{N6L Inhibits the Activation of the Wnt/ $\beta$-Catenin Pathway and Prevents $\beta$-Catenin Stabilization}

Orthotopic pancreatic tumors were induced by injecting mPDAC cells in FVB/n mice, and were treated with N6L $7 \mathrm{mg} / \mathrm{kg}$, as previously established and described in methods [2]. Mice were sacrified and tumor volume was measured, tumor growth was inhibited by N6L (Figure 6A), as previously described [2]. Tumors show a histopathology similar to human cancer, characterized by tumoral pancreatic ducts and a hypoxic, fibrotic tumor microenvironment, with a high heterogeneity of vessel density, as in human patients [2]. The rate of proliferative cells decreased in PDAC tumors treated with N6L compared with controls, while apoptotic cells increased (Figure 6B-D), as previously described [2]. $\beta$-catenin staining was high in tumor cells of control tumors, and did not change in N6Ltreated tumors (Figure 6B,E). Active $\beta$-catenin was analyzed by staining PDAC sections of control or N6L-treated mice with an antibody that recognized the non-phosphorylated form of $\beta$-catenin, as in 3D culture (Figure 6F). PDAC tumors showed a strong signal of active $\beta$-catenin specifically at the level of the tumor ductal cells (Figure 6G), suggesting 
that the pathway is active in vivo. N6L significantly and strikingly decreased the active $\beta$-catenin staining in tumor ductal cells (Figure 6F).

A
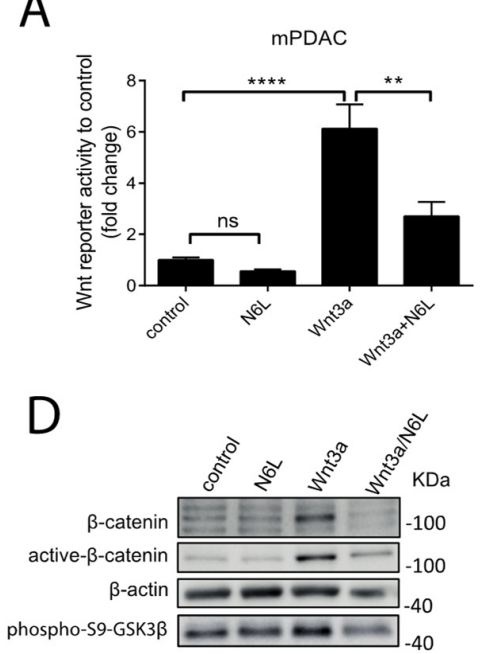

G

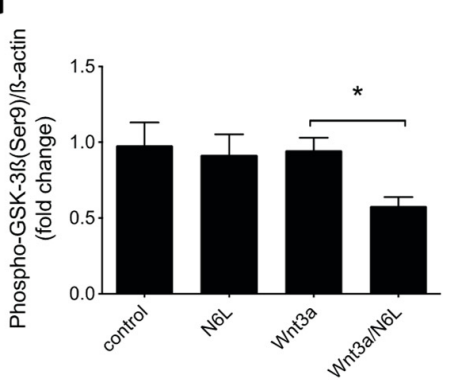

$J$

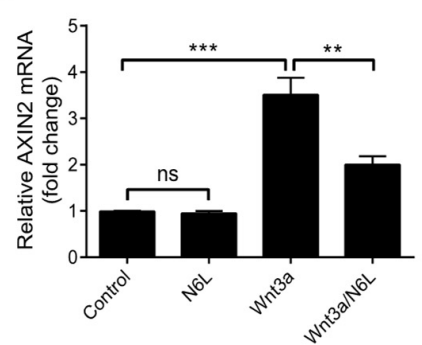

B

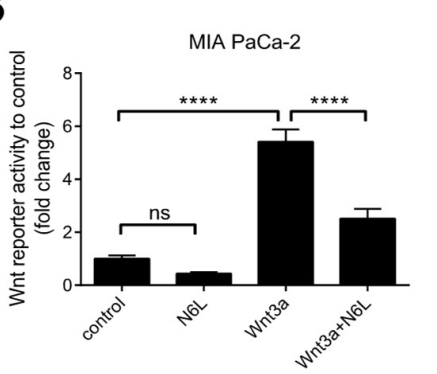

$\mathrm{E}$

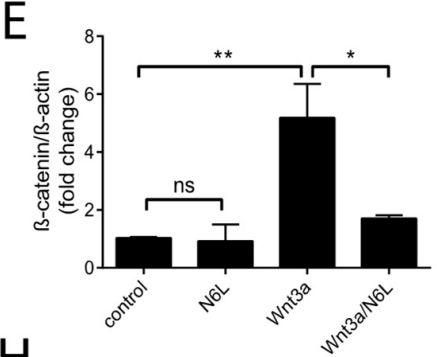

$\mathrm{H}$

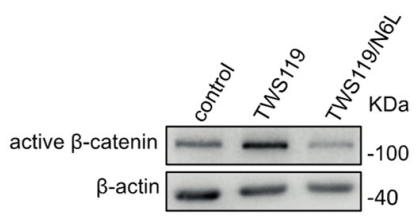

K

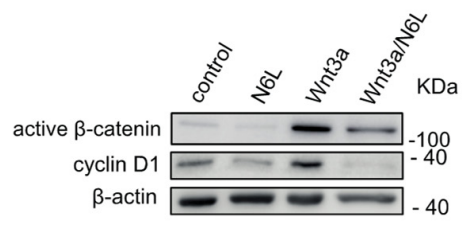

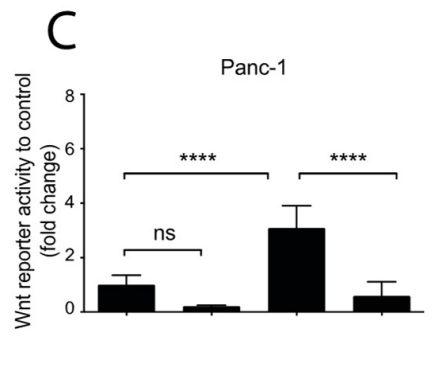

$\mathrm{F}$
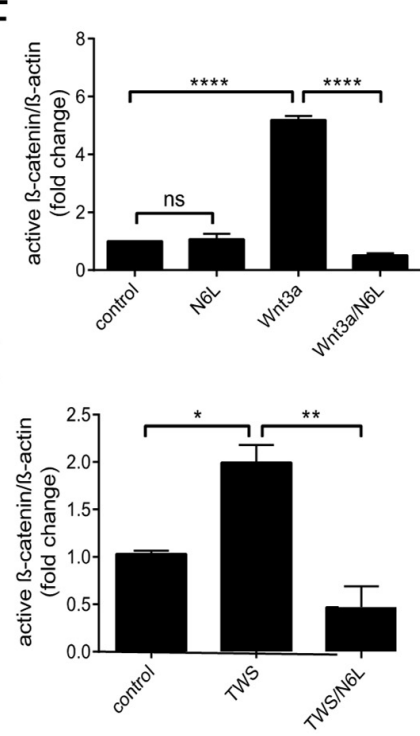

L

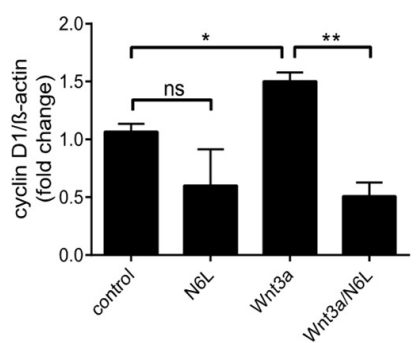

Figure 2. N6L inhibits $\beta$-catenin activation. (A-C) mPDACs, MIA PaCa-2 and Panc-1 cells were transfected with Firely luciferase Wnt reporter and Renilla luciferase for control and stimulated with Wnt3a-CM in presence or absence of N6L for $24 \mathrm{~h}$. Graphs show the fold change of the ratio of Firefly/Renilla luciferases activity (Dual-Luciferase Reporter Assay). Wnt3A-CM induced a significant increase of luciferase activity that was inhibited in presence of $30 \mu \mathrm{M}$ N6L in all cell lines. (One-way ANOVA, multiple comparison, $n=3$ experiments, ${ }^{* * * *} p<0.001$ ). (D-G) Western blotting of active, total $\beta$-catenin and phospho-Ser9-GSK3 $\beta$ of MIA PaCa- 2 cells treated for $3 \mathrm{~h}$ with N6L and Wnt3a-CM and relative quantification are shown. Active $\beta$-catenin was analyzed by using an antibody against non-phosphorylated form of $\beta$-catenin. In (E-G) (One way ANOVA, multiple comparison, $n=5$, ns = non-significant, $\left.{ }^{*} p<0.05,{ }^{* *} p<0.01,{ }^{* * * *} p<0.0001\right)$. (H,I) Western blotting and relative quantification of active $\beta$-catenin level of MIA PaCa-2 cells treated for 30 min with $10 \mu \mathrm{M}$ TWS119 alone or with $30 \mu \mathrm{M}$ N6L (One-way ANOVA, multiple comparison, $n=3,^{*} p<0.05,{ }^{* *} p<0.01$ ). (J) qPCR analysis of AXIN2 mRNA and $(\mathbf{K}, \mathrm{L})$ Cyclin D1 protein level analysis by Western blotting after $24 \mathrm{~h}$ of N6L treatment in presence of Wnt3A-CM compared to Wnt3a-CM alone. (One-way ANOVA, multiple comparison, $n=3$, ns = non-significant, ${ }^{*} p<0.05,{ }^{* *} p<0.01$, $^{* * *} p<0.005$ ). 

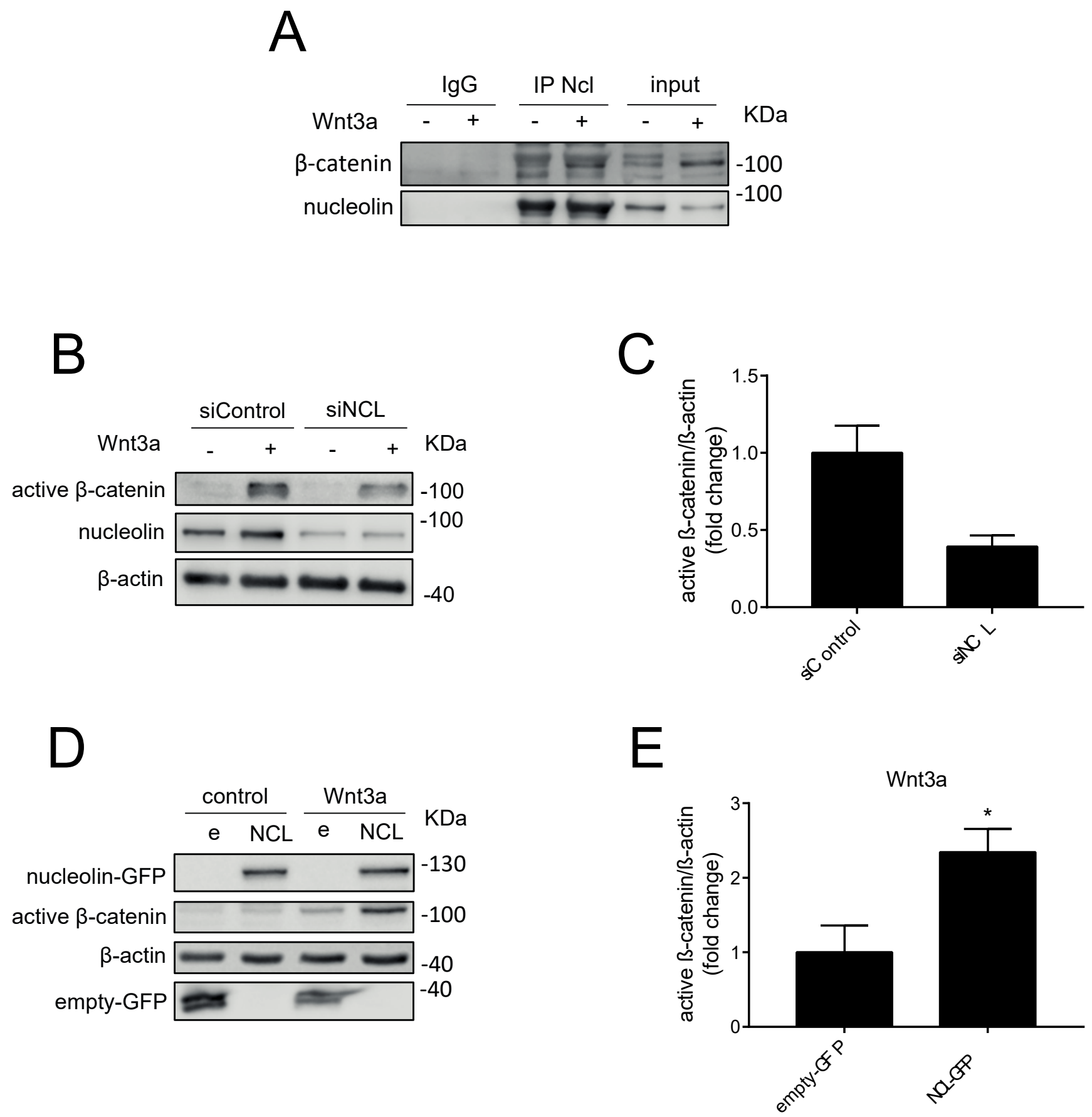

Figure 3. Nucleolin promotes $\beta$-catenin activation. (A) MIA PaCa-2 and Panc-1 cells were stimulated or not with Wnt3a-CM for $3 \mathrm{~h}$. Western blotting analysis of nucleolin immunoprecipitation (IP) or control IgG performed from the extranuclear fraction is shown. Anti-nucleolin confirmed the performance of the immunoprecipitation and anti- $\beta$-catenin the interaction between these two proteins. (B) MIA PaCa-2 cells were transfected with $20 \mathrm{nM}$ siNCL or with a control siRNA for $72 \mathrm{~h}$ and stimulated with or without Wnt3a-CM for $3 \mathrm{~h}$ before lysis. (D) MIA PaCa-2 cells were transfected with GFP-NCL (NCL) and GFP-empty. (e) plasmids for $72 \mathrm{~h}$. Cells were stimulated with or without Wnt3a-CM for $3 \mathrm{~h}$ before lysis. Western blotting analysis exhibited a stronger band of active $\beta$-catenin in cells with higher nucleolin expression than those with basal levels of the protein ( $n=3$ experiments). (C,E) Western blotting quantification of active $\beta$-catenin is shown. Active $\beta$-catenin was analyzed by using an antibody against non-phosphorylated form of $\beta$-catenin (two-tailed Mann-Whitney U-test, $n=3$ and $n=4$ experiments, $\left.{ }^{*} p<0.05\right)$. 
A

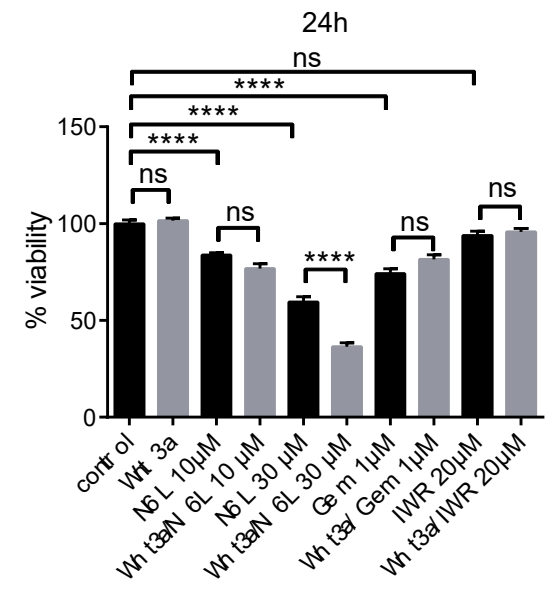

B

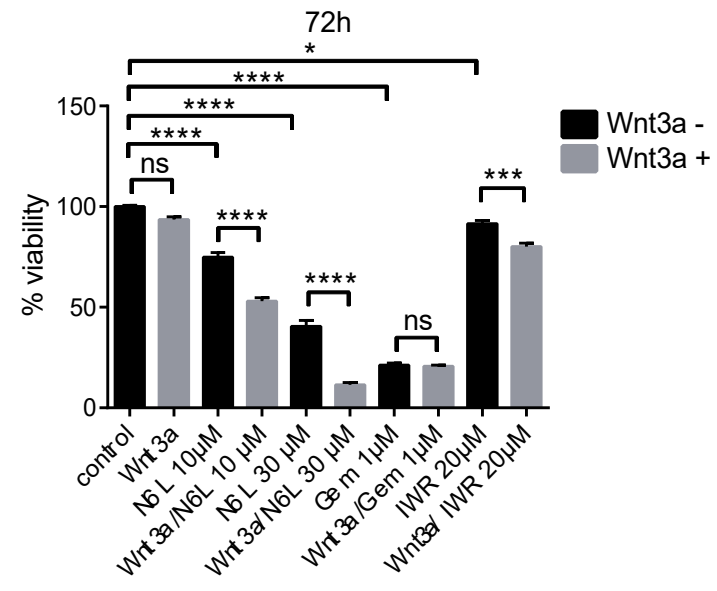

C

\begin{tabular}{|c|c|c|}
\hline $\begin{array}{c}\text { Wnt3Ain } \\
\text { combination with }\end{array}$ & Synergy (\%) & p-value \\
\hline $10 \mu \mathrm{MN6L}$ & $21 \% \pm 6+$ & $*$ \\
\hline $30 \mu \mathrm{MNGL}$ & $32 \% \pm 4 \%$ & $* * *$ \\
\hline $1 \mu \mathrm{M}$ Gem & $0 \% \pm 2 \%$ & ns \\
\hline $20 \mu \mathrm{M}$ IWR & $11 \% \pm 6 \%$ & $*$ \\
\hline
\end{tabular}

D

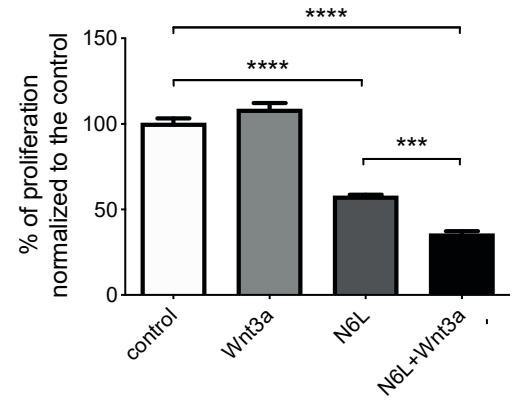

E

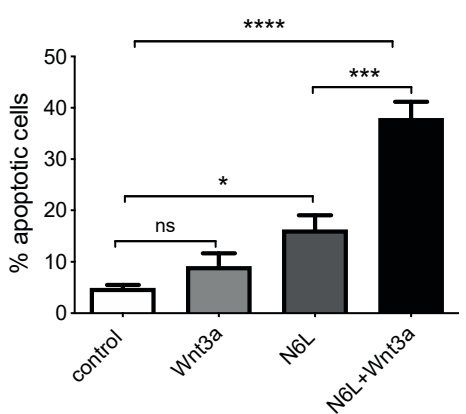

Figure 4. Wnt/ $\beta$-catenin pathway activation specifically sensitizes cells to N6L targeting. (A,B) MIA PaCa-2 cells were treated for 24 and $72 \mathrm{~h}$ with $10 \mu \mathrm{M}$ and $30 \mu \mathrm{M}$ N6L, $1 \mu \mathrm{M}$ gemcitabine or $20 \mu \mathrm{M}$ IWR-1-endo in presence or absence of Wnt3a-CM. Control cells were stimulated or not with Wnt3a-CM. Cell viability was analyzed as described in Materials and Methods. (One-way ANOVA, multiple comparison, $n=4$ experiments, $\mathrm{ns}=$ non-significant, ${ }^{*} p<0.05,{ }^{* * *} p<0.005$, ${ }^{* * * *} p<0.001$ ). (C) The synergy of the different combinations of treatments together with Wnt3a has been calculated by using the software Combenefit described in Materials and Methods. The score of synergy and the $p$-value are indicated in the table. (D) The effect of treatments on cell proliferation were evaluated by analayzing a cell tracer amount after $72 \mathrm{~h}$ and the graph indicates cell proliferation versus control cells. (E) After $24 \mathrm{~h}$ of treatment, apoptosis was evaluated by Annexin V staining and the graph indicates the $\%$ of apoptotic cells. (One-way ANOVA, multiple comparison, $n=4$ experiments in $(\mathbf{A}, \mathbf{B}), n=3$ experiments in (D,E), ns = non-significant, $\left.{ }^{*} p<0.05,{ }^{* * *} p<0.005,{ }^{* * * *} p<0.001\right)$. 


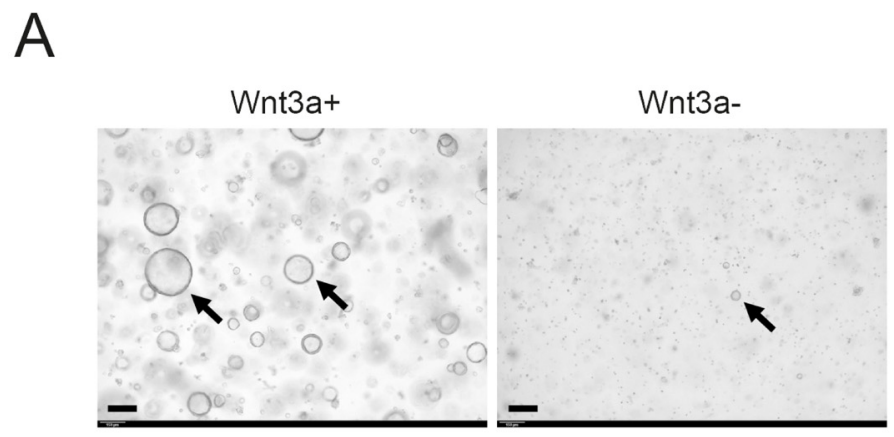

B
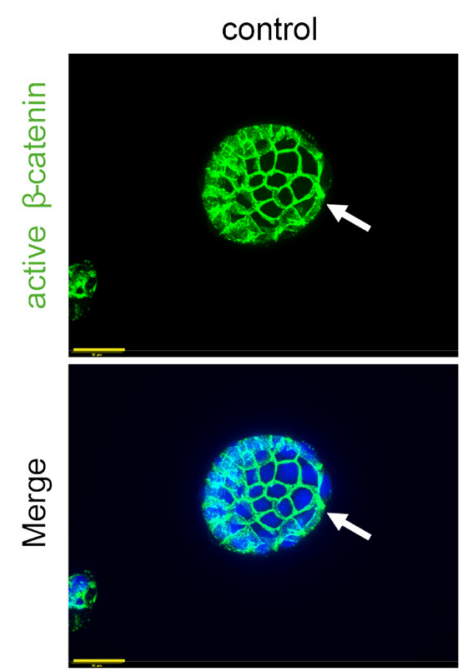

$\mathrm{E}$

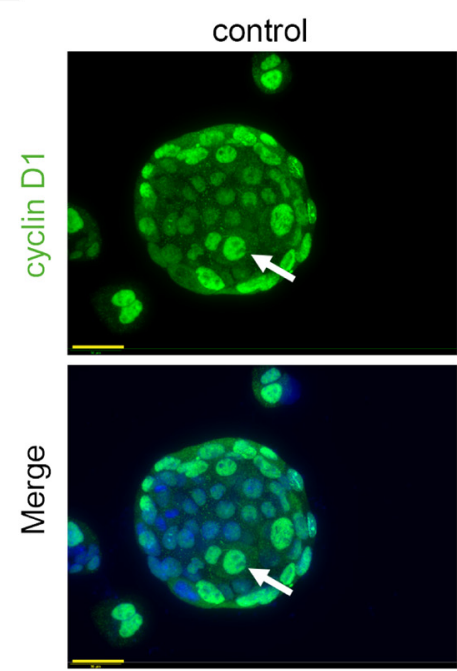

N6L
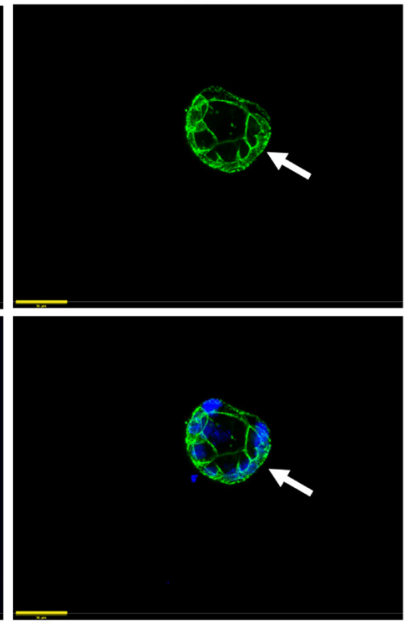

N6L
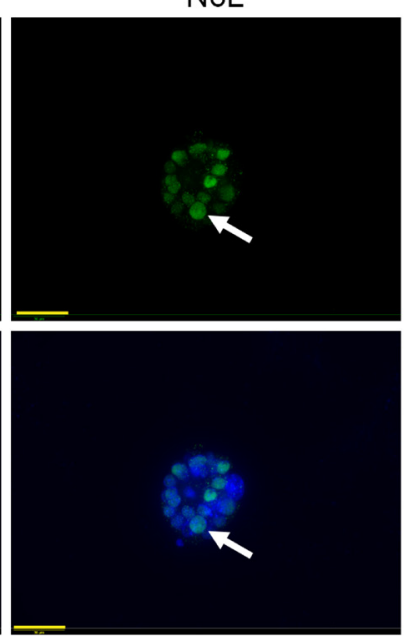

C

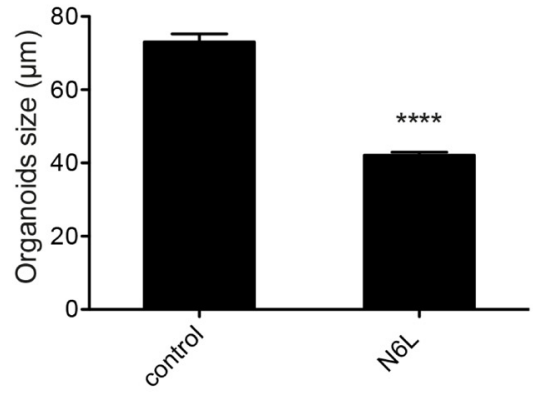

$\mathrm{D}$
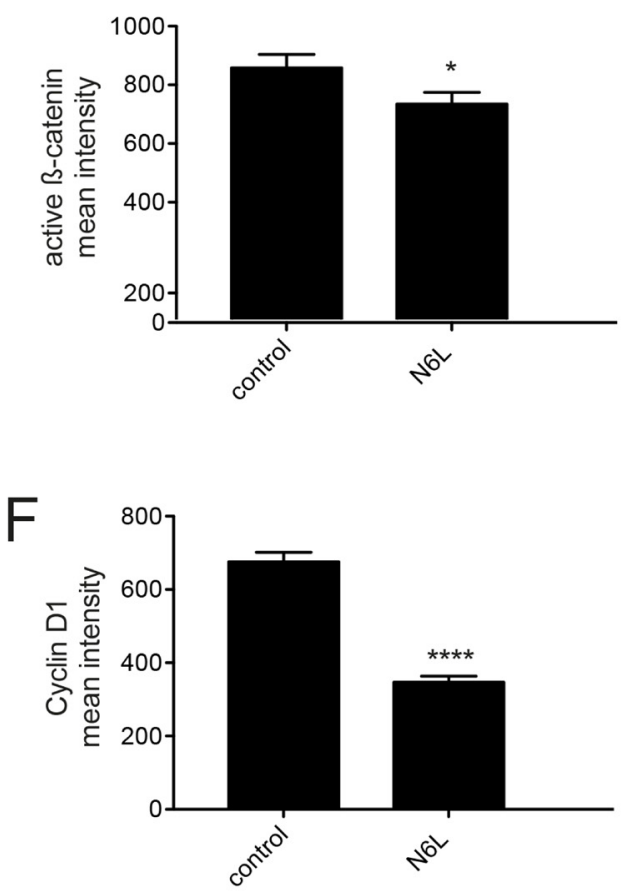

Figure 5. N6L inhibits Wnt/ $\beta$-catenin pathway in tumor-derived PDAC organoids. (A) Organoid cultures derived from MIA PaCa-2 tumors (arrows) were grown in human complete feeding medium (CFM) or complete feeding medium without Wnt3a-CM. (B,E) Immunofluorescence staining by anti-active $\beta$-catenin (green) and DAPI for nuclei (blue) or by anti-Cyclin D1 (green) and DAPI for nuclei (blue) in organoid culture grown in CFM treated or not with $30 \mu \mathrm{M} \mathrm{N6L}$. (C,D,F). Organoid size or active $\beta$-catenin signals or cyclin D1 nuclear signal in 3D culture treated or not with N6L were quantified (Two-tailed Student $t$ test, $\left.n=3,{ }^{*} p<0.05, * * * * p<0,001\right)$. Scale bars: $30 \mu \mathrm{M}$. 

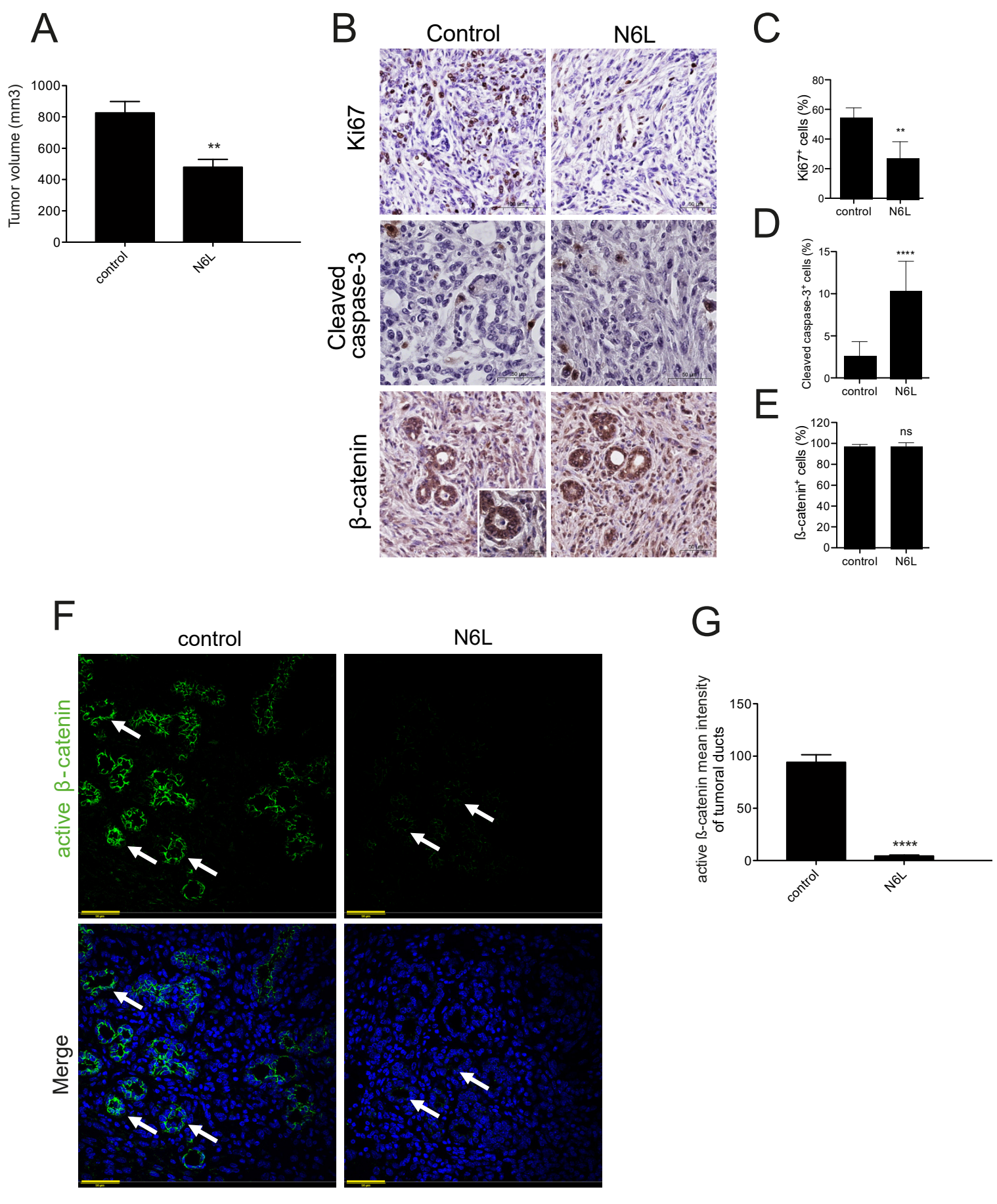

Figure 6. N6L inhibits Wnt/ $\beta$-catenin pathway in PDAC murine model. mPDAC cells were injected into the pancreas of $\mathrm{FVB} / \mathrm{n}$ mice, mice were treated with N6L and sacrificed after 3 weeks. (A) The volume of mPDAC tumors was measured (Student's $t$ test ${ }^{* *} p<0.01$ ). (B) Sections of mPDAC tumors were immunostained by using anti-Ki67, anti-cleaved caspase 3 or anti- $\beta$-catenin. The percentage of positive cells for each staining is shown in the graph (C-E) (Student's $t$ test ${ }^{* *} p<0.05$, $\left.{ }^{* * * *} p<0.001, n=4\right)$. (F) Sections of mPDAC tumors from mice treated with N6L or with PBS as control were stained by immunofluorescence with an anti-active $\beta$-catenin antibody (green) and DAPI for nuclei (blue). The intensity of active $\beta$-catenin staining is weaker in tumor ducts of tumors treated with N6L than the control. (G) Quantification of the mean grey value of active $\beta$-catenin staining in mPDAC tumoral ducts of control $(n=36)$ and N6L $(n=10)$ treated mice (Student's $t$ test $\left.{ }^{* * * *} p<0.001\right)$. Scale bars: $50 \mu \mathrm{M}$. 


\section{Discussion}

Nucleolin overexpression in human PDAC tumors is a negative prognostic factor for patients, and nucleolin inhibition by N6L inhibits PDAC growth and metastasis in tumor-bearing mice [2]. This work aimed to investigate new N6L interactors in pancreatic cancer, to explore the mechanisms of its antitumor activity, and develop new targetable pathways in this type of cancer. We showed for the first time that N6L interacts with $\beta$-catenin, and that nucleolin inhibition impairs $\mathrm{Wnt} / \beta$-catenin pathway activation by preventing $\beta$-catenin stabilization.

The study of the pull-down of N6L in PDAC cells allowed us to identify 45 proteins by mass-spectrometry. Nucleolin was present in the N6L pull-down, validating this approach for studying interactors of N6L. A total of $40 \%$ of the proteins of the N6L pull-down are known interactors of nucleolin, and $16 \%$ belong to the biological processes in which nucleolin is involved (regulation of rRNA processing and positive regulation of mRNA splicing via the spliceosome). We validated $\beta$-catenin, the key protein of the Wnt/ $\beta$-catenin pathway, as a new interactor of N6L and nucleolin by Western blotting in different PDAC cell lines. We also demonstrated an interaction of nucleolin and $\beta$ catenin in different human PDAC cells through immunoprecipitation studies. PDAC cells were stimulated with Wnt3A, the isoform commonly used to activate the Wnt/ $\beta$ catenin pathway $[30,34]$. The activation of the $\mathrm{Wnt} / \beta$-catenin pathway was followed by the accumulation of the non-phosphorylated $\beta$-catenin protein, and by the transcription of Wnt/ $\beta$-catenin pathway target genes. N6L prevented the stabilization of both forms of $\beta$-catenin in Wnt3A-responding PDAC cells. $\beta$-catenin is phosphorylated by CK1 and GSK3 $\beta$ before being ubiquitinated and successively degraded by the proteasome; the non-phosphorylated protein is, therefore, the form that is not degraded, and is considered the active form of the protein [41]. GSK3 $\beta$ is normally active in cells, and serine 9 phosphorylation as a negative regulation [42] was decreased by N6L in Wnt3A-stimulated cells, supporting that N6L could impact the phosphorylation of $\beta$-catenin and its degradation. In coherence with these data, AXIN2 mRNA and Cyclin D1 protein levels increased under Wnt3A stimulation, and their expression was prevented by N6L treatment in PDAC cells. In order to verify if N6L inhibited the pathway at the level of the activation of the receptor or more downstream in the signaling cascade, we used a GSK3 $\beta$ inhibitor, TWS119, that stabilizes $\beta$-catenin in a Wnt-independent way. TWS119 blocks the kinase activity of GSK $3 \beta$, preventing the triple phosphorylation of $\beta$-catenin on serines 33 and 37 and Threonine 41 , and degradation by the proteasome $[39,43,44]$. In this study, we showed that N6L prevents $\beta$-catenin stabilization induced by TWS119 in a Wnt ligand-independent way. This result supports that the inhibition does not occur at the receptor-ligand stage, but in the cytoplasm, downstream of GSK3 $\beta$. A previous study demonstrated that nucleolin promotes Wnt/GSK3 $\beta$ signals to regulate stem cell signaling in hemopoiesis [45]. The loss of function of nucleolin by siRNA inhibited Wnt/ $\beta$-catenin pathway activation similarly to N6L under Wnt3A stimulation. On the other hand, nucleolin overexpression increased $\beta$-catenin accumulation through Wnt3A in PDAC cells. These results suggest that the nucleolin protein level is important for the activation of the Wnt $\beta$-catenin pathway by Wnt3A. Indeed, nucleolin depletion impairs $\beta$-catenin stabilization and nucleolin overexpression induces $\beta$-catenin accumulation, meaning that nucleolin participates in the regulation of $\beta$-catenin degradation under pathway activation.

The importance of the Wnt/ $\beta$-catenin pathway is well known in tumor progression, invasion, and chemoresistance [27]. PDAC organoids from human patients have been demonstrated to be dependent to Wnt3A and R-spondin [37,46]. In this work, we have shown that the Wnt/ $\beta$-catenin pathway is necessary for the establishment and growth of tumor-derived 3D culture derived from MIA PaCa-2 tumors, and strong activation of $\beta$-catenin occurs in murine models of tumors and in the MIA PaCa-2 tumor-derived $3 \mathrm{D}$ culture. We also observed that human cell lines cultured in 2D are not dependent on exogenous Wnt3A stimulation for proliferation and survival, and this is probably due to the conditions of culture. Hyperactive Wnt signaling is associated with aberrant 
signaling in colorectal cancer, and also in breast and pancreatic cancers [47]. An increase in total $\beta$-catenin and Axin 2 has been observed in PDAC patients, and the Wnt pathway is one of the core signaling pathways most frequently dysregulated in PDAC [48-50]. Here, we showed that the majority of PDAC patients have an elevated level of $\beta$-catenin active form, supporting the idea that the $\mathrm{Wnt} / \beta$-catenin pathway is broadly activated in PDAC. MIA PaCa-2 tumor-derived 3D cultured in the presence of Wnt3A showed a strong signal of active $\beta$-catenin concomitant to an increase of nuclear Cyclin D1 localization and accumulation. N6L treatment inhibited the growth of MIA PaCa-2 tumor-derived $3 \mathrm{D}$ culture and decreased active $\beta$-catenin and nuclear Cyclin D1 signals. Wnt ligands are expressed by stromal cells during pancreas tumorigenesis [46] and in the orthotopic PDAC mouse models, similarly to in PDAC patients, and the Wnt/ $\beta$-catenin pathway is strongly active in ductal tumor cells. Importantly, N6L treatment is able to decrease the active $\beta$-catenin signal in tumoral ducts. In $3 \mathrm{D}$ culture and tumor sections from murine PDAC and patients, active $\beta$-catenin localizes mainly in the cytoplasm, as in other human tumors in which cytoplasmic $\beta$-catenin correlates with a poor prognosis [51,52].

Wnt inhibitors inhibit the Wnt/ $\beta$-catenin pathway and cancer cell growth through the impairment of $\beta$-catenin stabilization $[44,53,54]$. Since clinical data show that elevated Wnt signaling correlates with a worse outcome for a subset of human cancers, a number of inhibitors targeting the Wnt pathway have advanced to clinical trials [47,55]. Some of these inhibitors have been shown to affect the growth of mouse models of PDAC in pre-clinical studies [56-58]. These inhibitors could also have an impact on the demonstrated Wnt signaling-mediated cancer therapy resistance. Nucleolin acts as a co-receptor for several growth factors and participates in different signaling pathways sustaining tumor cell growth, prompting several laboratories, including ours, to design synthetic nucleolin antagonists [4]. The nucleolin antagonist N6L selectively binds to nucleolin [5] and decreases tumor growth $[2,5,7,10,13]$. N6L inhibits PDAC cell proliferation, inducing cell apoptosis in mouse models and PDAC cells [2]. N6L inhibits MIA PaCa-2 cell proliferation and induced apoptosis, and this effect in 2D culture is independent of Wnt signaling because Wnt/ $\beta$-catenin is not active in these cells [31]. However, the N6L anti-proliferative and pro-apoptotic effect was higher and synergic when the Wnt/ $\beta$-catenin pathway was activated by Wnt3A. Cells with an active Wnt/ $\beta$-catenin pathway did not respond better to gemcitabine compared to non-activated cells. This suggests that N6L acts on PDAC viability by blocking different pathways and that its effect is stronger when the Wnt $/ \beta$-catenin pathway is active. This point is particularly important since we have shown that $\beta$-catenin is active in the majority of PDAC patients and because other researchers have shown Wnt $/ \beta$-catenin pathway activation plays a role in drug resistance in PDAC cancer $[59,60]$. PDAC tumors with strongly active $\beta$-catenin could better respond to N6L treatment. Moreover, since the potential side effects of Wnt/ $\beta$-catenin inhibitors are unclear, N6L could be a new potential drug for regulating $\beta$-catenin stabilization and activation.

In this work, we showed that N6L inhibits the Wnt/ $\beta$-catenin signaling pathway in PDAC cell lines, tumor-derived 3D culture, and mouse models by preventing the stabilization of $\beta$-catenin. Nucleolin could promote the stabilization of $\beta$-catenin by interfering with the activity of GSK3 $\beta$, which normally leads to $\beta$-catenin degradation. N6L, by inhibiting nucleolin, it may promote the degradation of $\beta$-catenin, leading to the inhibition of the Wnt $/ \beta$-catenin pathway.

\section{Materials and Methods}

\subsection{Cell Culture}

Murine pancreatic cancer cells (mPDAC) were cultured as previously described (Gilles et al., 2016) [2]. MIA PaCa-2, PAnc-1, and L-Wnt-3A cells were purchased from ATCC (Manassas, VA, USA) and cultured according to the manufacturer's instructions. Wnt3a conditioned medium (Wnt3a-CM) was produced and recovered as described by Shibamoto et al. [30], and 50\% Wnt3a-CM was added to basal cell medium to activate the Wnt/ $\beta$-catenin pathway. 


\subsection{Cell Growth Assay}

A total of $5 \times 10^{3}$ MIA PaCa-2 cells/well were plated in 96-multiwell plates. The day after, the cells were treated with $10 \mu \mathrm{M}$ N6L, $30 \mu \mathrm{M}$ N6L, $1 \mu \mathrm{M}$ Gemcitabine (Mylan SAS France), or $20 \mu \mathrm{M}$ IWR-1-endo (Santa Cruz, Dallas, TX, USA) in the presence or absence of Wnt3a-CM 1:2 for 24 and $72 \mathrm{~h}$. Cell viability was analyzed by Alamar Blue Assay, as previously described [2]. Cell proliferation was analyzed by adding CellTrace reagents (Thermofisher, Waltham, MA, USA), following the manufacturer's instructions, with $2 \times 10^{5}$ MIA PaCa-2 cells/well plated in 6-multiwell plates. Cell apoptosis was analyzed by incorporating Annexin V (eBioscience, San Diego, CA, USA) with $1.5 \times 10^{5}$ MIA PaCa-2 cells/well plated in 6-multiwell plates. To determine possible additive and synergistic effects when using combinations, the data from cell viability assays were analyzed using the freely available software, Combenefit (High Single Agent model) [36]. The software calculates a synergy score for each combination, where a positive score indicates synergy, a score of 0 is additive, and a negative score indicates antagonism.

\section{3. $R T-q P C R$}

$1 \times 10^{6}$ MIA PaCa-2 cells were plated in $100 \mathrm{~mm}$ Petri dishes and treated for $24 \mathrm{~h}$ with Wnt3a-CM 1:2, with or without $30 \mu \mathrm{M}$ N6L. Cells were lysed and total RNA was purified using a PureLink RNA Mini Kit (Life Technologies, Waltham, MA, USA), according to the manufacturer's instructions. Total RNA (100 ng) was reverse-transcribed using hexamer random primers and a first-strand cDNA synthesis kit (Fermenta, Thane, Maharashtra, India), and the synthesized cDNA was analyzed by qPCR using FastStart Universal SYBR Green Master (Roche, Basel, Switzerland). Primers used: AXIN2 (Fw: 5'GCTGACGGATGATTCCATGT3', Rev: 5'ACTGCCCACACGATAAGGAG3') and $\beta$ ACTIN (Fw: 5'GTTACAGGAAGTCCCTTGCCATCC $3^{\prime}$, Rev: 5'CACCTCCCCTGTGTGGA CTTGGG3').

\subsection{Cell Transfection}

For siRNA transfection, $8 \times 10^{4}$ MIA PaCa-2 cells/well were plated in 6-multiwell plates. The day after, cells were transfected for $72 \mathrm{~h}$ with $20 \mathrm{nM}$ NCL siRNA (Interchim, Montluçon, France) for nucleolin or luciferase control siRNA (Qiagen, Hilden, Germany), by using Lipofectamine RNAiMAX (Invitrogen, Waltham, MA, USA). For plasmid transfection, $1.2 \times 10^{6}$ MIA PaCa-2 cells/well were plated in 6-multiwell plates and transfected for $72 \mathrm{~h}$ with $5 \mu \mathrm{g}$ NCL-GFP (nucleolin) or empty-GFP (control), provided by E.M. Reyes-Reyes (University of Arizona, Tucson, AZ, USA), using Lipofectamine 3000 (Thermo Fisher).

\subsection{Dual-Luciferase Reporter Assay}

A total of $8 \times 10^{5}$ mPDAC, MIA PaCa-2, and Panc- 1 cells/well were seeded in 6multiwell plates. A Cignal TCF/LEF Reporter Assay Kit (Qiagen, CCS-018L), containing Firefly and Renilla plasmids, was used according to the manufacturer's instructions, using Lipofectamine 3000 (Thermo Fisher). The activities of both Firefly and Renilla luciferase reporters were determined $72 \mathrm{~h}$ after transfection and $24 \mathrm{~h}$ after treatment with Wnt3a-CM and $30 \mu \mathrm{M}$ N6L alone or together, using a Dual-Luciferase Assay Kit (Promega, Madison, WI, USA) according to the manufacturer's instructions. The reporter activity is presented as the relative ratio of Firefly luciferase activity to Renilla luciferase activity.

\subsection{Immunoprecipitation}

A total of $8 \times 10^{6}$ MIA PaCa-2 and Panc- 1 cells were plated in $75 \mathrm{~cm}^{2}$ flasks. The day after, cells were stimulated or not with Wnt3a-CM for $3 \mathrm{~h}$, and lysed using the same lysis buffer as for the pull-down. One mg of proteins of the extra-nuclear fraction was incubated with $5 \mu \mathrm{g}$ rabbit anti-nucleolin antibody (Abcam ab22758) or $5 \mu \mathrm{g}$ control rabbit IgG (Jackson, 011-000-002) for $1 \mathrm{~h}$ at $4{ }^{\circ} \mathrm{C}$ by mixing samples. Protein $\mathrm{G}$ sepharose beads (Millipore, Burlington, MA, USA) were prepared and added to the protein/antibody 
solution, according to the manufacturer's instructions. After washing, the proteins were eluted and analyzed by Western blotting.

\subsection{Western Blotting}

A total of $4 \times 10^{5}$ MIA PaCa-2 cells were plated in 6-multiwell plates. The day after, cells were treated for 3 or $24 \mathrm{~h}$ with 1:2 Wnt3a-CM, with or without $30 \mu \mathrm{M}$ N6L. Otherwise, cells were treated for $30 \mathrm{~min}$ with $10 \mu \mathrm{M}$ TWS-119 (Santa Cruz), with or without $30 \mu \mathrm{M}$ N6L. Cells were lysed with Laemmli buffer, and protein samples were separated by SDS-PAGE and transferred onto a $0.45 \mu \mathrm{M}$ Immobilon-P membrane (Millipore) following standard protocols. Membranes were blocked with $5 \% w / v$ BSA (Sigma, Burlington, MA, USA) in TBS 0.1\% TWEEN-20 (VWR, Radnor, PA, USA) and incubated with the indicated antibodies. Immunocomplexes were visualized by using the luminescence blotting substrate ECL Pierce (Roche). Chemiluminescence was imaged by an imager system (LI-COR Odyssey Fc, Lincoln, NE, USA). Signal quantification was undertaken with Image Studio Lite (version 5.2), and expressed as the fold change relative to control. The original western blotting figures can be found in Figure S5.

\subsection{Pancreatic Tumor Mouse Models and MIA PaCa-2 Tumour-Derived 3D Culture}

mPDAC cells $\left(1 \times 10^{3}\right.$ cells/mouse in $50 \mu \mathrm{L}$ PBS $)$ were injected orthotopically into the pancreas of $\mathrm{FVB} / \mathrm{n}$ syngeneic mice, as previously described [2]. One week after cell inoculation, the mice were treated three times a week for the duration of 2 weeks by intraperitoneal injections with $7 \mathrm{mg} / \mathrm{kg}$ N6L or vehicle (saline solution) as a control. The protocol of treatment has been previously established, we defined as a starting point to perform a regression trial one week after cancer cells inoculation, a time period in which tumors reached a volume of approximately $80 \mathrm{~mm}^{3}$ [2]. The mice were sacrificed and total tumor size was measured as previously described [2].

MIA PaCa-2 cells $\left(1 \times 10^{7}\right.$ cells / mouse in $\left.50 \mu \mathrm{L}\right)$ were injected orthotopically into the pancreas of immunodeficient mice. The mice were sacrificed after 4 weeks and tumorderived 3D culture were established by following Tuveson's laboratory protocol [37]. Briefly, tumors were digested with $0.012 \%(w / v)$ collagenase XI (Sigma) and $0.012 \%(w / v)$ dispase (Gibco, Waltham, MA, USA) in DMEM media containing 1\% FBS (Gibco), and the resulting cell suspension was incorporated into growth factor-reduced Matrigel (Corning, Corning, NY, USA) to obtain a 3D culture.

All in vivo experiments were carried out with the approval of the appropriate ethical committee and under conditions established by the European Union.

\subsection{Immunofluorescence and Immunohistochemistry}

Tumour-derived 3D cultures established from MIA PaCa2 tumors grown in immunodeficient mice were seeded in $\mu$-Plate 96-well black (ibidi, Gräfelfing, Germany) in 10\% growth factor-reduced Matrigel (Corning). After $48 \mathrm{~h}$, Tumour-derived 3D cultures were treated or not with $30 \mu \mathrm{M}$ N6L for $24 \mathrm{~h}$, were fixed in $4 \%$ paraformaldehyde (Thermo Scientific), permeabilized with $0.1 \%$ Triton-x100 (VWR), and blocked with 10\% donkey serum (Jackson). Primary antibodies and secondary antibodies (Thermo Scientific D1306, 1:400) were diluted in in $0.3 \%$ BSA and incubated at $37^{\circ} \mathrm{C}$ in a humid chamber for $1 \mathrm{~h}$. Immunofluorescence pictures were acquired using a DSU IX81 spinning-disc confocal inverted microscope (Olympus, Tokyo, Japan) equipped with a $40 \times$ oil objective. Analysis and quantification of active $\beta$-catenin and cyclin D1 mean intensity was undertaken with ImageJ software.

Immunofluorescence of $5 \mu \mathrm{M}$ mouse tumor slices from paraffin-embedded blocks was performed as previously described [61] by using the primary antibody for active $\beta$-catenin. The mean grey intensity of active $\beta$-catenin for each tumoral duct was measured with ImageJ, and normalized with the area of the corresponding duct.

Immunohistochemistry was performed on $5 \mu \mathrm{M}$ mPDAC sections, dewaxed, and stained for Ki67 (Abcam ab15580, 1:500), cleaved caspase-3 (Cell Signalling, France \#9661, 
1:400), and $\beta$-catenin (Sigma Aldrich C2206, 1:1500). Antigen retrieval was performed with Dewax and HIER Buffer L (Thermo Scientific TA-999-DHBL) for 20 min at $95{ }^{\circ} \mathrm{C}$. Slices were blocked with BLOXALL Endogenous Blocking Solution (VECTOR Laboratories, Burlingame, CA, USA SP-6000) for $10 \mathrm{~min}$, and saturated with Blocking Solution (Zytomed, Germany ZUC007) for $5 \mathrm{~min}$ at room temperature. Sections were incubated with primary antibodies diluted in Antibody Diluent (Zytomed ZUC025) for $1 \mathrm{~h}$, and with an ImmPRESS HRP Horse Anti-Rabbit IgG Polymer Detection Kit (VECTOR Laboratories MP-7401) for $30 \mathrm{~min}$, and with ImmPACT DAB (VECTOR Laboratories SK-4105) for $10 \mathrm{~min}$ at room temperature. Images were acquired with a NanoZoomer S360 digital slide scanner (Hamamatsu, Japan C13220-01).

\subsection{Statistical Analysis}

Statistical analyses were performed by using GraphPad Prism (San Diego, CA, USA) (version 6). The bars represent the mean $\pm \operatorname{SEM}(n \geq 3)$. For continuous variables, we first tested both normality and equality of variance. In the case of a normal distribution, parametric statistical tests were used; otherwise, we used non-parametric tests. For twogroup comparisons, we analyzed the data using the two-tailed Student $t$-test. For multiple group comparisons, 1-way ANOVA Rank with the Dunn method was used $\left({ }^{*} p<0.05\right.$, $\left.{ }^{* *} p<0.01,{ }^{* * *} p<0.005,{ }^{* * * *} p<0.001\right)$.

\section{Conclusions}

This work aimed to define the mechanism of the nucleolin antagonist N6L in the treatment of pancreatic ductal adenocarcinoma (PDAC). We claim here, for the first time, that both N6L and nucleolin interact with $\beta$-catenin, and that nucleolin targeting by N6L or siRNA leads to the inhibition of the Wnt/ $\beta$-catenin pathway by preventing $\beta$-catenin stabilization in human PDAC cell lines. These results have been validated in tumor-derived 3D culture and a PDAC mouse model.

Supplementary Materials: The following are available online at https:/ /www.mdpi.com/article/ 10.3390/cancers13122986/s1, Figure S1: Biotinylated-N6L pull-down; Figure S2: N6L interactome; Figure S3: MIA PaCa-2 and Panc- 1 cell comparison; Figure S4: Active $\beta$-catenin staining in PDAC patients; Figure S5: The original western blotting figures; Table S1: Mass-spectrometry analysis of N6L pull-down proteins; Table S2: Gene ontology (GO) analysis of N6L pull-down proteins.

Author Contributions: Conceptualization, F.R. and I.C.; methodology, F.R., I.C., S.B.-V., M.C., D.H., C.H., A.D. and M.B.; validation, F.R., M.C. and M.C.-D.; formal analysis, F.R., S.B-V., M.C., M.C.-D. and I.C.; investigation, F.R., S.B.-V., M.C., D.H., M.P., C.H., B.V., M.C.-D. and P.B.; resources, M.C.-D. and M.B.; data curation, F.R., A.C. and S.B.-V.; writing-original draft preparation, F.R.; writingreview and editing, S.B.-V., M.C. and I.C.; visualization, F.R. and I.C.; supervision, I.C., J.C. (José Courty); project administration, I.C.; funding acquisition, J.L.C., J.C. (Jerome Cros), and I.C. All authors have read and agreed to the published version of the manuscript.

Funding: This research was funded by the "Ligue National contre le Cancer", "ANR-16-CE17-0023THERANUC", with the joint grant "PAIR PANCREAS" from the "Ligue National contre le Cancer", "ARC", and "INCA".

Institutional Review Board Statement: The study was conducted according to the guidelines of the Declaration of Helsinki and approved by the Institutional Review Board (or Ethics Committee) of US Department of Health and Human Services ( $n^{\circ}$ IRB 00003835, 28 January 2010).

Informed Consent Statement: Informed consent was obtained from all subjects involved in the study.

Data Availability Statement: The data presented in this study are available on request from the corresponding author.

Conflicts of Interest: The authors declare no conflict of interest. 


\section{References}

1. Siegel, R.L.; Miller, K.D.; Jemal, A. Cancer statistics, 2019. CA Cancer J. Clin. 2019, 69, 7-34. [CrossRef]

2. Gilles, M.-E.; Maione, F.; Cossutta, M.; Carpentier, G.; Caruana, L.; Di Maria, S.; Houppe, C.; Destouches, D.; Shchors, K.; Prochasson, C.; et al. Nucleolin Targeting Impairs the Progression of Pancreatic Cancer and Promotes the Normalization of Tumor Vasculature. Cancer Res. 2016, 76, 7181-7193. [CrossRef]

3. Storck, S.; Shukla, M.; Dimitrov, S.; Bouvet, P. Functions of the Histone Chaperone Nucleolin in Diseases. Prokaryotic Cytoskeletons 2007, 41, 125-144. [CrossRef]

4. Berger, C.M.; Gaume, X.; Bouvet, P. The roles of nucleolin subcellular localization in cancer. Biochimie 2015, 113, 78-85. [CrossRef]

5. Destouches, D.; Page, N.; Hamma-Kourbali, Y.; Machi, V.; Chaloin, O.; Frechault, S.; Birmpas, C.; Katsoris, P.; Beyrath, J.; Albanese, P.; et al. A Simple Approach to Cancer Therapy Afforded by Multivalent Pseudopeptides That Target Cell-Surface Nucleoproteins. Cancer Res. 2011, 71, 3296-3305. [CrossRef]

6. Destouches, D.; Sader, M.; Terry, S.; Marchand, C.; Maillé, P.; Soyeux, P.; Carpentier, G.; Semprez, F.; Céraline, J.; Allory, Y.; et al. Implication of NPM1 phosphorylation and preclinical evaluation of the nucleoprotein antagonist N6L in prostate cancer. Oncotarget 2016, 7, 69397-69411. [CrossRef] [PubMed]

7. De Cola, A.; Franceschini, M.; Di Matteo, A.; Colotti, G.; Celani, R.; Clemente, E.; Ippoliti, R.; Cimini, A.; Dhez, A.; Vallée, B.; et al. N6L pseudopeptide interferes with nucleophosmin protein-protein interactions and sensitizes leukemic cells to chemotherapy. Cancer Lett. 2018, 412, 272-282. [CrossRef]

8. Ramos, K.S.; Moore, S.; Runge, I.; Tavera-Garcia, M.A.; Cascone, I.; Courty, J.; Reyes-Reyes, E. The Nucleolin Antagonist N6L Inhibits LINE1 Retrotransposon Activity in Non-Small Cell Lung Carcinoma Cells. J. Cancer 2020, 11, 733-740. [CrossRef]

9. Benedetti, E.; Antonosante, A.; d'Angelo, M.; Cristiano, L.; Galzio, R.; Destouches, D.; Florio, T.M.; Dhez, A.C.; Astarita, C.; Cinque, B.; et al. Nucleolin antagonist triggers au-tophagic cell death in human glioblastoma primary cells and decreased in vivo tumor growth in orthotopic brain tumor model. Oncotarget 2015, 6, 42091-42104. [CrossRef]

10. Dhez, A.-C.; Benedetti, E.; Antonosante, A.; Panella, G.; Ranieri, B.; Florio, T.M.; Cristiano, L.; Angelucci, F.; Giansanti, F.; Di Leandro, L.; et al. Targeted therapy of human glioblastoma via delivery of a toxin through a peptide directed to cell surface nucleolin. J. Cell. Physiol. 2018, 233, 4091-4105. [CrossRef]

11. Sanhaji, M.; Göring, J.; Couleaud, P.; Aires, A.; Cortajarena, A.L.; Courty, J.; Prina-Mello, A.; Stapf, M.; Ludwig, R.; Volkov, Y.; et al. The phenotype of target pancreatic cancer cells influences cell death by magnetic hyperthermia with nanoparticles carrying gemicitabine and the pseudo-peptide NucAnt. Nanomed. Nanotechnol. Biol. Med. 2019, 20, 101983. [CrossRef] [PubMed]

12. Belbekhouche, S.; Cossutta, M.; Habert, D.; Hamadi, S.; Modjinou, T.; Cascone, I.; Courty, J. N6L-functionalized nanoparticles for targeted and inhibited pancreatic cancer cells. Colloids Surf. A Physicochem. Eng. Asp. 2020, 607, 125461. [CrossRef]

13. Diamantopoulou, Z.; Gilles, M.-E.; Sader, M.; Cossutta, M.; Vallée, B.; Houppe, C.; Habert, D.; Brissault, B.; Leroy, E.; Maione, F.; et al. Multivalent cationic pseudopeptide polyplexes as a tool for cancer therapy. Oncotarget 2017, 8, 90108-90122. [CrossRef] [PubMed]

14. Cheriyamundath, S.; Ben-Ze'Ev, A. Wnt/ $\beta$-Catenin Target Genes in Colon Cancer Metastasis: The Special Case of L1CAM. Cancers 2020, 12, 3444. [CrossRef] [PubMed]

15. Polakis, P. Wnt Signaling in Cancer. Cold Spring Harb. Perspect. Biol. 2012, 4, a008052. [CrossRef]

16. Spiegelman, V.S.; Slaga, T.J.; Pagano, M.; Minamoto, T.; Ronai, Z.; Fuchs, S.Y. Wnt/ $\beta$-Catenin Signaling Induces the Expression and Activity of $\beta \operatorname{TrCP}$ Ubiquitin Ligase Receptor. Mol. Cell 2000, 5, 877-882. [CrossRef]

17. He, X.; Semenov, M.; Tamai, K.; Zeng, X. LDL receptor-related proteins 5 and 6 in Wnt/ $\beta$-catenin signaling:Arrows point the way. Development 2004, 131, 1663-1677. [CrossRef]

18. Logan, C.Y.; Nusse, R. The Wnt signaling pathway in development and disease. Annu. Rev. Cell Dev. Biol. 2004, 20, 781-810. [CrossRef]

19. Gordon, M.D.; Nusse, R. Wnt Signaling: Multiple Pathways, Multiple Receptors, and Multiple Transcription Factors. J. Biol. Chem. 2006, 281, 22429-22433. [CrossRef] [PubMed]

20. Wu, D.; Pan, W. GSK3: A multifaceted kinase in Wnt signaling. Trends Biochem. Sci. 2010, 35, 161-168. [CrossRef]

21. Jiang, H.; Li, Q.; He, C.; Li, F.; Sheng, H.; Shen, X.; Zhang, X.; Zhu, S.; Chen, H.; Chen, X.; et al. Activation of the Wnt pathway through Wnt2 promotes metastasis in pancreatic cancer. Am. J. Cancer Res. 2014, 4, 537-544. [PubMed]

22. Modi, S.; Kir, D.; Banerjee, S.; Saluja, A. Control of Apoptosis in Treatment and Biology of Pancreatic Cancer. J. Cell. Biochem. 2016, 117, 279-288. [CrossRef] [PubMed]

23. Nan, J.N.; Kim, O.R.; Lee, M.A. $\beta$-Catenin expression is associated with cell invasiveness in pancreatic cancer. Korean J. Intern. Med. 2019, 34, 618-625. [CrossRef]

24. Zhang, Y.; Morris, J.P.; Yan, W.; Schofield, H.K.; Gurney, A.; Simeone, D.M.; Millar, S.E.; Hoey, T.; Hebrok, M.; Di Magliano, M.P. Canonical Wnt Signaling Is Required for Pancreatic Carcinogenesis. Cancer Res. 2013, 73, 4909-4922. [CrossRef]

25. Callebaut, C.; Jacotot, E.; Guichard, G.; Krust, B.; Rey-Cuille, M.-A.; Cointe, D.; Benkirane, N.; Blanco, J.; Muller, S.; Briand, J.-P.; et al. Inhibition of HIV Infection by Pseudopeptides Blocking Viral Envelope Glycoprotein-Mediated Membrane Fusion and Cell Death. Virology 1996, 218, 181-192. [CrossRef]

26. Koutsioumpa, M.; Drosou, G.; Mikelis, C.; Theochari, K.; Vourtsis, D.; Katsoris, P.; Giannopoulou, E.; Courty, J.; Petrou, C.; Magafa, V.; et al. Pleiotrophin expression and role in physiological angiogenesis in vivo: Potential involvement of nucleolin. Vasc. Cell 2012, 4, 4. [CrossRef] [PubMed] 
27. Makena, M.R.; Gatla, H.; Verlekar, D.; Sukhavasi, S.; Pandey, M.K.; Pramanik, K.C. Wnt/ $\beta$-Catenin Signaling: The Culprit in Pancreatic Carcinogenesis and Therapeutic Resistance. Int. J. Mol. Sci. 2019, 20, 4242. [CrossRef]

28. Bindea, G.; Galon, J.; Mlecnik, B. CluePedia Cytoscape plugin: Pathway insights using integrated experimental and in silico data. Bioinformatics 2013, 29, 661-663. [CrossRef]

29. Bindea, G.; Mlecnik, B.; Hackl, H.; Charoentong, P.; Tosolini, M.; Kirilovsky, A.; Fridman, W.-H.; Pagès, F.; Trajanoski, Z.; Galon, J. ClueGO: A Cytoscape plug-in to decipher functionally grouped gene ontology and pathway annotation networks. Bioinformatics 2009, 25, 1091-1093. [CrossRef]

30. Shibamoto, S.; Higano, K.; Takada, R.; Ito, F.; Takeichi, M.; Takada, S. Cytoskeletal reorganization by soluble Wnt-3a protein signalling. Genes Cells 1998, 3, 659-670. [CrossRef]

31. Toyoda, E.; Doi, R.; Koizumi, M.; Kami, K.; Ito, D.; Mori, T.; Fujimoto, K.; Nakajima, S.; Wada, M.; Imamura, M. Analysis of E-, $\mathrm{N}-$ Cadherin, $\alpha-, \beta-$, and $\gamma$-Catenin Expression in Human Pancreatic Carcinoma Cell Lines. Pancreas 2005, 30, 168-173. [CrossRef]

32. Sarkar, S.; Mandal, C.; Sangwan, R.; Mandal, C. Coupling G2/M arrest to the Wnt/ $\beta$-catenin pathway restrains pancreatic adenocarcinoma. Endocr.-Relat. Cancer 2014, 21, 113-125. [CrossRef]

33. Romero, D.; Iglesias, M.; Vary, C.P.H.; Quintanilla, M. Functional blockade of Smad4 leads to a decrease in $\beta$-catenin levels and signaling activity in human pancreatic carcinoma cells. Carcinogenesis 2008, 29, 1070-1076. [CrossRef]

34. Farin, H.F.; Jordens, I.; Mosa, M.H.; Basak, O.; Korving, J.; Tauriello, D.V.F.; De Punder, K.; Angers, S.; Peters, P.J.; Maurice, M.M.; et al. Visualization of a short-range Wnt gradient in the intestinal stem-cell niche. Nature 2016, 530, 340-343. [CrossRef]

35. Chen, B.; E Dodge, M.; Tang, W.; Lu, J.; Ma, Z.; Fan, C.-W.; Wei, S.; Hao, W.; Kilgore, J.; Williams, N.S.; et al. Small molecule-mediated disruption of Wnt-dependent signaling in tissue regeneration and cancer. Nat. Chem. Biol. 2009, 5, 100-107. [CrossRef]

36. Di Veroli, G.Y.; Fornari, C.; Wang, D.; Mollard, S.; Bramhall, J.L.; Richards, F.M.; Jodrell, D.I. Combenefit: An interactive platform for the analysis and visualization of drug combinations. Bioinformatics 2016, 32, 2866-2868. [CrossRef]

37. Boj, S.F.; Hwang, C.-I.; Baker, L.A.; Chio, I.I.C.; Engle, D.D.; Corbo, V.; Jager, M.; Ponz-Sarvise, M.; Tiriac, H.; Spector, M.S.; et al. Organoid models of human and mouse ductal pancreatic cancer. Cell 2015, 160, 324-338. [CrossRef] [PubMed]

38. Tiriac, H.; Belleau, P.; Engle, D.D.; Plenker, D.; Deschênes, A.; Somerville, T.D.D.; Froeling, F.E.M.; Burkhart, R.A.; Denroche, R.E.; Jang, G.H.; et al. Organoid Profiling Identifies Common Responders to Chemotherapy in Pancreatic Cancer. Cancer Discov. 2018, 8, 1112-1129. [CrossRef] [PubMed]

39. Kafri, P.; Hasenson, S.E.; Kanter, I.; Sheinberger, J.; Kinor, N.; Yunger, S.; Shav-Tal, Y. Quantifying $\beta$-catenin subcellular dynamics and cyclin D1 mRNA transcription during Wnt signaling in single living cells. Elife 2016, 5, e16748. [CrossRef] [PubMed]

40. Xue, X.; Shah, Y.M. In vitro Organoid Culture of Primary Mouse Colon Tumors. J. Vis. Exp. 2013, 17, e50210. [CrossRef] [PubMed]

41. Nusse, R.; Brown, A.; Papkoff, J.; Scambler, P.; Shackleford, G.; McMahon, A.; Moon, R.; Varmus, H. A new nomenclature for int-1 and related genes: The Wnt gene family. Cell 1991, 64, 231. [CrossRef]

42. Beurel, E.; Grieco, S.F.; Jope, R.S. Glycogen synthase kinase-3 (GSK3): Regulation, actions, and diseases. Pharmacol. Ther. 2015, 148, 114-131. [CrossRef] [PubMed]

43. Chen, Y.-Q.; Zheng, L.; Aldarouish, M.; Zhou, Z.-H.; Pan, N.; Liu, J.-Q.; Chen, F.-X.; Wang, L.-X. Wnt pathway activator TWS119 enhances the proliferation and cytolytic activity of human $\gamma \delta$ T cells against colon cancer. Exp. Cell Res. 2018, 362, 63-71. [CrossRef] [PubMed]

44. Pramanik, K.C.; Fofaria, N.M.; Gupta, P.; Ranjan, A.; Kim, S.-H.; Srivastava, S.K. Inhibition of $\beta$-Catenin signaling suppresses pancreatic tumor growth by disrupting nuclear $\beta$-Catenin/TCF-1 complex: Critical role of STAT-3. Oncotarget 2015, 6, 11561-11574. [CrossRef] [PubMed]

45. Reister, S.; Mahotka, C.; van den Höfel, N.; Grinstein, E. Nucleolin promotes Wnt signaling in human hematopoietic stem/progenitor cells. Leukemia 2019, 33, 1052-1054. [CrossRef] [PubMed]

46. Seino, T.; Kawasaki, S.; Shimokawa, M.; Tamagawa, H.; Toshimitsu, K.; Fujii, M.; Ohta, Y.; Matano, M.; Nanki, K.; Kawasaki, K.; et al. Human Pancreatic Tumor Organoids Reveal Loss of Stem Cell Niche Factor Dependence during Disease Progression. Cell Stem Cell 2018, 22, 454-467.e6. [CrossRef]

47. Zhong, Z.; Virshup, D.M. Wnt Signaling and Drug Resistance in Cancer. Mol. Pharmacol. 2020, 97, 72-89. [CrossRef] [PubMed]

48. Zeng, G.; Germinaro, M.; Micsenyi, A.; Monga, N.K.; Bell, A.; Sood, A.; Malhotra, V.; Sood, N.; Midda, V.; Monga, D.K.; et al. Aberrant Wnt/ $\beta$-Catenin Signaling in Pancreatic Adenocarcinoma. Neoplasia 2006, 8, 279-289. [CrossRef] [PubMed]

49. Lowe, A.W.; Olsen, M.; Hao, Y.; Lee, S.P.; Lee, K.T.; Chen, X.; Van De Rijn, M.; Brown, P.O. Gene Expression Patterns in Pancreatic Tumors, Cells and Tissues. PLoS ONE 2007, 2, e323. [CrossRef]

50. Jones, S.; Zhang, X.; Parsons, D.W.; Lin, J.C.-H.; Leary, R.J.; Angenendt, P.; Mankoo, P.; Carter, H.; Kamiyama, H.; Jimeno, A.; et al. Core Signaling Pathways in Human Pancreatic Cancers Revealed by Global Genomic Analyses. Science 2008, 321, $1801-1806$. [CrossRef]

51. López-Knowles, E.; Zardawi, S.J.; McNeil, C.M.; Millar, E.K.; Crea, P.; Musgrove, E.A.; Sutherland, R.L.; O’Toole, S.A. Cytoplasmic Localization of $\beta$-Catenin is a Marker of Poor Outcome in Breast Cancer Patients. Cancer Epidemiol. Prev. Biomark. 2010, 19, 301-309. [CrossRef] [PubMed]

52. Santoro, A.; Pannone, G.; Papagerakis, S.; McGuff, H.S.; Cafarelli, B.; Lepore, S.; De Maria, S.; Rubini, C.; Mattoni, M.; Staibano, S.; et al. Beta-Catenin and Epithelial Tumors: A Study Based on 374 Oropharyngeal Cancers. BioMed Res. Int. 2014, $2014,948264$. [CrossRef] [PubMed] 
53. Huang, J.; Qu, Q.; Guo, Y.; Xiang, Y.; Feng, D. Tankyrases/ $\beta$-catenin Signaling Pathway as an Anti-proliferation and Antimetastatic Target in Hepatocarcinoma Cell Lines. J. Cancer 2020, 11, 432-440. [CrossRef] [PubMed]

54. Talar, B.; Gajos-Michniewicz, A.; Talar, M.; Chouaib, S.; Czyz, M. Pentoxifylline Inhibits WNT Signalling in $\beta$-Cateninhigh Patient-Derived Melanoma Cell Populations. PLoS ONE 2016, 11, e0158275. [CrossRef] [PubMed]

55. Zhan, T.; Rindtorff, N.; Boutros, M. Wnt signaling in cancer. Oncogene 2017, 36, 1461-1473. [CrossRef] [PubMed]

56. Jang, B.G.; Lee, B.L.; Kim, W.H. Distribution of LGR5 + Cells and Associated Implications during the Early Stage of Gastric Tumorigenesis. PLoS ONE 2013, 8, e82390. [CrossRef] [PubMed]

57. Gurney, A.; Axelrod, F.; Bond, C.J.; Cain, J.; Chartier, C.; Donigan, L.; Fischer, M.; Chaudhari, A.; Ji, M.; Kapoun, A.M.; et al. Wnt pathway inhibition via the targeting of Frizzled receptors results in decreased growth and tumorigenicity of human tumors. Proc. Natl. Acad. Sci. USA 2012, 109, 11717-11722. [CrossRef] [PubMed]

58. Fischer, M.M.; Cancilla, B.; Yeung, V.P.; Cattaruzza, F.; Chartier, C.; Murriel, C.L.; Cain, J.; Tam, R.; Cheng, C.-Y.; Evans, J.W.; et al. WNT antagonists exhibit unique combinatorial antitumor activity with taxanes by potentiating mitotic cell death. Sci. Adv. 2017, 3, e1700090. [CrossRef]

59. Cao, J.; Ma, J.; Sun, L.; Li, J.; Qin, T.; Zhou, C.; Cheng, L.; Chen, K.; Qian, W.; Duan, W.; et al. Targeting glypican-4 overcomes 5-FU resistance and attenuates stem cell-like properties via suppression of Wnt/ $\beta$-catenin pathway in pancreatic cancer cells. J. Cell. Biochem. 2018, 119, 9498-9512. [CrossRef]

60. Wang, B.; Zou, Q.; Sun, M.; Chen, J.; Wang, T.; Bai, Y.; Chen, Z.; Chen, B.; Zhou, M. Reversion of trichostatin A resistance via inhibition of the Wnt signaling pathway in human pancreatic cancer cells. Oncol. Rep. 2014, 32, 2015-2022. [CrossRef]

61. Cossutta, M.; Darche, M.; Carpentier, G.; Houppe, C.; Ponzo, M.; Raineri, F.; Vallée, B.; Gilles, M.-E.; Villain, D.; Picard, E.; et al. Weibel-Palade Bodies Orchestrate Pericytes During Angiogenesis. Arterioscler. Thromb. Vasc. Biol. 2019, 39, 1843-1858. [CrossRef] [PubMed] 